\title{
1895-1898: INGLATERRA Y LA BUSQUEDA DE UN COMPROMISO INTERNACIONAL PARA FRENAR LA INTERVENCION NORTEAME- RICANA EN CUBA '
}

\author{
por \\ ROSARIO DE LA TORRE DEL RÍo \\ Universidad Complutense de Madrid
}

RESUMEN: Tomando como referencias la bibliografía especializada y un amplio conjunto de fuentes archivisticas, fundamentalmente británicas, este artículo comienza analizando la nueva situación internacional que caracteriza la última década del siglo $x I X$, las lineas generales de la politica exterior española y la posición intemacional de Inglaterra como consecuencia de su necesidad de hacer compatible la defensa de su posición en el Pacífico con el reforzamiento de la seguridad de Gibraltar cuando se formaliza la alianza franco-rusa. Sobre esta base, la decisión española de no renovar los Acuerdos Mediterráneos, el estallido de la insurrección cubana, los primeros pasos de la intervención norteamericana y los continuados esfuerzos españoles para lograr la intervención de las grandes potencias en general, y de Inglaterra en particular, para frenar al gobierno de Washington, fueron la ocasión de la intervención de sir Henry Drammond Wolff, embajador británico en Madrid, que intentó empujar al gobierno del marqués de Salisbury en favor de los objetivos de los sucesivos gobiemos españoles. Aunque no tenga exito, la intensa actividad de Wolff $y$ su abundante correspondencia con el Foreign Office permite conocer no sólo las líneas generales de la diplomacia que las grandes potencias en general -y Inglaterra en particular- desarrollaron en Madrid, sino también las perspectivas, los objetivos y las iniciativas de la politica exterior española en los años que precedieron al «Desastren.

1 Este trabajo, que se inscribe en los proyectos de investigación financiados por la DGICYT titulados: «El contexto internacional del «98» español» (PS 91-0003) y «La crisis española del 98 y su vertiente mediterránean (PS 94-0050), desarrolla y documenta con mayor detalle algura de las cuestiones presentadas de manera mas resumida en mi reciente trabajo: «La situación internacional de los años 90 y la política exterior españolan, en: Fusı, J. P. y Niño, A. (eds.), Visperas del 98 . Ortgenes y antecedentes de la crisis del 98, Madrid, Biblioteca Nueva, 1997, págs. 173-193. 
Palabras ClaVe. Historia de las Relactones Internactonales. Historia Contemporánea. Siglo xux. 1895-1898. España. Inglaterra. Gibraltar. Estados Unidos. Cuba. Negoclación diplomática. Intervenctón internacional, Garantía intexnacional. Acuer. dos Mediterráneos. Henry Drummond Wolff.

ABSTRACT: «1895-1898: England and the Search for an International Agreement to Prevent American Intervention in Cubas: Using specialized bibliography and ample archival sources, mainly British, this article analyzes the new international situation during the last decade of the nineteenth century, the general guidelines of Spanish foreign policy, and Britain's international position as well as her need of strengthen the security of Gibraltar when the FrancoRussian alliance came. In this point, the Spanish decision not to renew the Mediterranean Agreements, the outbreak of the Cuban insurrection, the initial steps leading to American intervention, and Spain's attempt to persuade the great European powers to intervene in order to check the Washington government, will cause the British embassador in Madrid to try to move Lord Salisbury's government in Spain's favour. Although he was not successful, Wolff's intense activity and his abundant correspondence with the Foreign Office show not only the European powers' diplomacy in Madrid, but also the perspectives, gaols and initiatives of Spanish foreign policy in the years preceding the "Disaster".

KEY wORDS: History of International Relations. Modern History. 19th Century. 1895-1898. Spain. Britain. Gibrartar. United States. Cuha. Diplomatic Negotiation. International Intervention. International Guarantee. Mediterranean Agreements. Henry Drummond Wolff.

Desde que estalló la última insurrección cubana en 1895 hasta que comenzó la guerra con los Estados Unidos en 1898, el principal empeño de la diplomacia española fue lograr una garantía de las grandes potencias europeas en general y de Inglaterra en particular que impidiese la intervención de la potencia norteamericana en el conflicto. Como la articulación de la estrategia conducente al logro de ese empeño debía hacerse desde la base que proporcionaba la herencia de la política exterior de la Restauración y en medio de las condiciones internacionales de la última década del siglo XIX, conviene que empecemos este estudio teniendo en cuenta herencias políticas, condiciones internacionales y posición de Inglaterra.

\section{LA hERENCIA DE LA POLf́tica EXTERIOR DE LA RESTAURACIÓN}

La España de la Restauración elaboró su política exterior desde una cierta consideración de los profundos cambios ocurridos en Europa en los años 
1870/73. Consciente de que no era posible la continuidad con la política exterior de los moderados, Cánovas del Castillo buscó, en la segunda mitad de los años setenta, la seguridad de la Monarquía en la conexión con la Europa que empezaba a liderar la Alemania bismarckiana. El recogimiento canovista intentó evitar tanto el aislamiento como el compromiso mientras se esforzaba en presentar una buena imagen externa del Estado español y en mantener y mejorar las relaciones con las potencias. Los liberales, cuya política dominó los años ochenta, tampoco pudieron enlazar con la política de Sexenio ya que, a los cambios producidos en 1870/73, había que añadir, en los años ochenta, las consecuencias de la implantación en Europa de un sólido sistema internacional bajo preponderancia alemana. Mas allá de la retórica de la ejecución, la política exterior de los liberales girará también en torno a Alemania.

Visto desde España, el período histórico que se había abierto con la derrota francesa en Sedan presentaba un rasgo fundamental: la decadencia de los pueblos latinos y la plenitud de los pueblos nórdicos, anglosajones y germanos. No es extraño que un profundo sentimiento de decadencia, que cornpartío firmemente Antonio Cánovas del Castillo, el fundador del nuevo régimen político, impregnase de un vivo pesimismo el pensamiento internacional de la España de la Restauración. Realmente, si colocamos a España en el plano de la política mundial, el pesimismo aparecerá plenamente justificado en razón de la dificultades de una época en la que la fortaleza creciente de las grandes potencias del momento disminuye la pequeña potencia de España. Sin embargo, ese sentimiento pesimista será compatible con el sentimiento de orgullo nacional que se derivaba de la creencia en que el pueblo español constituía una comunidad definida históricamente como excepcional. Una espontánea capacidad de indignación frente al atropello, que se mostrará particularmente sensible a cuestiones de prestigio que afectaban a la integridad del territorio nacional, y una interpretación de la historia de España unilateral y esquemática, que se construyó sobre una línea ininterrumpida de batallas victoriosas, serán las bases de ese orgullo nacional ${ }^{2}$.

Sobre la base del recogimiento canovista, la política exterior de la Restauración intentó alcanzar tres grandes objetivos y se articuló sobre cuatro constantes. La salvaguardia del Régimen, la prevención de una acción de otra potencia en Marruecos y la conservación de las colonias del Caribe y del Pacífico fueron los tres grandes objetivos compartidos por los dos partidos turnantes en el poder. Pero más allá de la búsqueda de estos tres grandes objetivos, la política exterior de la Restauración se articuló, de hecho, sobre cuatro constantes: la fuerza de un conjunto de vínculos de tipo económico, ideológico y cultural que ligaban a España con Francia e Inglaterra y que configuraban estados y tendencias de la opinión pública; la muy difícil relación

2 JOVER ZAMORA, José María: «Los caracteres de la política exterior de España en el siglo XIX». En: Política, diplomacia y humanismo popular en la España del siglo XIX. Madrid, Turner, 1976, págs. 122-125; y «La época de la Restauración. Panorama político-social, 1875-1902». En: Revolución burguesa, oligarquía y constitucionalismo (1834-1923), vol. VIII de la Historia de España dirigida por TuÑón DE LARA, Manuel. Barcelona, Labor, 1981, págs. 269-406. 
con la Tercera República Francesa como consecuencia del peligro que provenía de la emigración política española instalada en su suelo; la orientación decidida, fundada en la defensa del principio monárquico, hacia los Imperios Centrales en general y hacia Alemania en particular y, por último, las dificultades que se derivaban de una política bismarckiana que potenciaba la política colonial francesa en el norte de Africa. Tres grandes objetivos y cuatro constantes que, en parte, se contradicen ${ }^{3}$.

Los liberales de Práxedes Mateo Sagasta no consiguieron sacar a la política exterior de la Restauración de esta contradicción aunque la firma de los Acuerdos Mediterráneos, un subsistema en conexión con el sistema continental de la Triple Alianza, proporcione a España la ocasión de un acercamiento al sistema bismarckiano. Las Notas de 6 de mayo de 1887 intercambiadas por los Gobiernos de Roma y Madrid son poco más que declaraciones antifrancesas en favor del statu quo del Mediterráneo Occidental. El acuerdo no suponía ni reconocimiento de los intereses españoles ni, por supuesto, garantía de los mismos. Su finalidad era la de fortalecer el principio monárquico y contribuir a la consolidación de la paz mediante el compromiso, por parte de España, de no llegar a ningún acuerdo con Francia que pudiera ser entendido como dirigido contra cualquiera de las potencias firmantes de la Triple; los compromisos recíprocos se limitaban a la abstención de todo ataque no provocado y al mantenimiento del statu quo del Mediterráneo Occidental.

Si los gobiernos de Sagasta no fueron capaces de sacar a la política exterior de la Restauración de la profunda contradicción en la que se había metido, la prematura muerte de Alfonso XII y las perspectivas de una larga Regencia en manos de María Cristina de Habsburgo-Lorena concentró todavía más todos los esfuerzos exteriores en el reforzamiento del principio monárquico: en la salvaguardia de un Régimen que a los ojos de propios y extraños aparecía como especialmente frágil. A principios de los noventa, el principio monarquico seguía siendo muy manejado en la correspondencia diplomática aunque sea muy discutible que la nueva situación internacional permita a las grandes potencias tenerlo en cuenta a la hora de tomar sus decisiones. Así, en 1890, en el contexto de la crisis portuguesa del ultimatum, las especulaciones de los monarcas de las grandes potencias no se limitaron a considerar las consecuencias revolucionarias que la crisis podría causar en Portugal; el gran duque de Baden, el príncipe de Gales y el emperador alemán se convirtieron en mediadores entre la Dinastía portuguesa y la Corona britá. nica

«... interesados sólo de manera secundaria en la profetizada revolución en Portugal. Su importancia (de la posible revolución portuguesa), a sus ojos, residía en su provable extensión a España, cuya salida de la anarquía constitucional crónica tenía escasamente el tiempo de una generación. Su rey era un niño. La

3 SALom Costa, Julio: España en la Europa de Bismark. Madrid, CSIC, 1967, y «La Restauración y la politica exterior de Españan, en: Corona y Diplomacia. La Monarquia española en la historia de las relaciones intemacionales. Madrid. Escuela Diplomática, 1988, págs. 137-182.

Hispanie, LVI1/2, núm. 196 (1997) 515-549 


\begin{abstract}
joven viuda austriaca de Alfonso XII lleva el gobierno con políticos ampliamente corruptos e inevitablemente facciosos; con una opinión pública desgarrada en fragmentos opuestos por los cismas de los años anteriores; enfrentada a un descontento popular creciente; ella misma, como extranjera, sospechosa y dudosa ante todos los partidos por igual. El coraje y el talento con los que, en solitaria auto-dependencia e inspirada sólo por su lealtad de madre, mantiene su lucha en favor del orden y la cohesion bajo estas desventajas, ha suscitado un fuerte sentimiento de simpatía personal hacia ella en Europa - una simpatía que se ha visto reforzada por el recuerdo del desorden civil sin fin que hasta ahora ha sido la consecuencia normal de los trastornos políticos en Españan 4.
\end{abstract}

Más allá de las exageraciones que sin duda encierra, este texto refleja muy bien, a mi juicio, la percepción exterior de la fragilidad del Régimen de la Regencia, una percepción muy generalizada entre los dirigentes europeos que ayuda a entender el papel central que, en las especulaciones nacionales e internacionales de 1898 jugará el futuro de la Dinastía que reinaba en España. Por otro lado, no lo olvidemos, si la Regente y el Rey-nin̄o podían concitar la solidaridad de la Europa monárquica de finales del siglo XIX, la Regencia agravaba el concepto patrimonial de la Monarquía restaurada; la preservación de la integridad del patrimonio heredado por el Rey-niño parecía ser la principal obligación de la Regencia, con lo que cualquier reconocimiento de la independencia de cualquier colonia ponía en entredicho, de entrada, la misma legitimidad del Régimen y, por eso mísmo, amenazaba su estabilidad.

\title{
INGLATERRA Y LA NUEVA SITUACIÓN INTERNACIONAL DE LOS AÑOS 90
}

Con sus errores y sus aciertos, la política exterior de la Restauración había tratado de amoldarse a las condiciones creadas por la política bismarckiana. Pero la caída de Bismarck, el 18 de marzo de 1890, marcará el inicio de un viraje en la política exterior del Reich alemán cuyas consecuencias transformarán por completo el panorama internacional de los años noventa ${ }^{5}$. Bajo la influencia de von Holstein, el Gobierno de Berlín renunciará a mantener un lazo secreto con Rusia y abandonará el rasgo esencial de la política bismarckiana. A partir de ese momento empezará a prepararse el acontecimiento que marcará la historia internacional europea de la década: el Imperio Ruso, aislado, orientará su política hacia la alianza con la Francia republicana. La polí-

4 CEClL, Lady Gwendolen: Life of Robert Marquis of Salisbury, Londres, Hodders \& Stoughton, 4 vols., 1921-1932, vol. IV (1887-1892), pág. 271.

5 GIRAULT, R.: Diplomatie européenne et impérialismes (187/-1914). Vol. I de la colección Relations internationales contemporaines. París, Masson, 1979. LANGER, L.W.: The Diplomacy of Imperialism: 1890-1902. Nueva York, 1951. LANGHORNE, R:: The Collapse of the Concert of Europe. International Politic 1890-19/4. Londres, Macmillan Press, 1981. MuLzA, Pierre: Les relations internationales de 187I à 1914, París, Armand Colin, 1990. Renouvin, Pierre: Historia de las relaciones intemacionales. Siglos xIX y xx. Madrid, Akal, 1982. TAYLOR, A. J. P.: The Struggle for Mastery in Europe, 1848-1918. Oxford, Clarendon Press, 1954. 
tica francesa de los empréstitos rusos había preparado el terreno y cuando la ocasión se presente, el Gobierno de París se aferrará a ella. La renovación de la Triple Alianza el 6 de mayo de 1891 y las simultáneas alusiones del Gobierno italiano a los Acuerdos Mediterráneos de 1887 terminarán de decidir al Zar de Rusia.

La situación europea establecida por el tratado de Frankfurt y mantenida gracias al sistema bismarckiano se fue transformado con el restablecimiento de un equilibrio entre los Estados continentales; las posibilidades que se le ofrecerían en lo sucesivo a la política alemana habían quedado limitadas. Si bien la alianza era sólo defensiva y el Zar había tenido buen cuidado en no comprometerse con los deseos del Gobierno de París de preparar la recuperación de Alsacia y Lorena, los franceses experimentaron una fuerte sensación de alivio y un fuerte sentimiento de confianza espoleó su política de expansión colonial. Asegurada en el continente, Francia podían lanzarse fuera de él sin la necesidad de contar con la buena voluntad del Gobierno alemán. La política francesa podía tener en adelante una mayor autonomía en las empresas mundiales, lo que sin duda inquietaría a los intereses británicos.

Aunque su Imperio se extendiese sobre una cuarta parte de la superficie terrestre, los británicos de la última década del siglo xix serán conscientes de que aquel esplendor imperial era compatible con un cambio general muy peligroso para su posición en el mundo ${ }^{6}$. En efecto, cuando, en la época moderna, comenzó la lucha por los territorios ultramarinos, Inglaterra se encontró bien colocada para sacar ventaja en el comercio intemacional; su insularidad le protegió y su flota le garantizó frente a invasiones y fue instrumento de dominio comercial; después, logrará establecer una sociedad relativamente bien ordenada con un sistema legal que favorecerá el ascenso de la burguesía y la formación de unas elites que apoyarán la expansión ultramarina. El camino emprendido había culminado entre 1815 y 1865, con la hegemonía británica en la industria y el comercio; pero, hacia 1865, Inglaterra habia llegado a su cenit como potencia mundial y comenzará a percibir los signos del ocaso. En las tres o cuatro últimas décadas del siglo XIX la posición británica como potencia industrial de primer orden declinó rápidamente mientras otros Estados avanzaron en los campos de la manufactura y la tecnología. La conciencia de ese declinar será el principal condicionante de la formulación de la política exterior del país ?

La extensión de la industrialización fue posiblemente el factor que influyó de manera mas poderosa en la política internacional de la segunda mitad del siglo XIX por la gran alteración que introdujo en el equilibrio mundial; Esta-

6 Bourne, K.: The Foreign Policy of Victorian England 1830-1902, Londres, 1970; ELDRIDGE, C. C. (ed.): British Imperialism in the Nineteenth Century, Londres, 1984; CHAMBERLAIN, Muriel E.: 'Pax Britannica'? British Foreign Policy 1789-1914. Londres, Longman, 1988; BARTLETT, C. 1.: Defence and Diplomacy. Britain and the Great Powers 1815-19/4, Manchester University Press, 1993.

7 KENNEDY, Paul: Realities behind Diplomacy: Background Influence on British External Policy 1865-1980, Fontana Paperbacks, 1981, págs. 17-27.

Hispania, LVII/2, núm. 196 (1997) 515-549 
dos Unidos fue asumiendo una posición cada vez mas dominante en el hemisferio occidental mientras decrecía el monopolio comercial británico en el Caribe y en Latinoamérica; Rusia se industrializó hasta ser capaz de construir un ferrocarril a través del cual podía presionar militarmente y de manera directa sobre India y China. Pues bien, todos estos cambios implicaban una disminución evidente de la influencia británica que se venía a añadir a la que se estaba produciendo como consecuencia de un reparto colonial que terminaba con una parte importante del dominio informal que Inglaterra había venido disfrutando en Africa y Asia.

En particular, la política colonial francesa habia venido preocupando a Inglaterra. La diplomacia británica no había cesado de vigilarla y obstaculizarla y, aunque los conflictos no fueron graves, para contener a Francia, Inglaterra había recurrido a Alemania en varias ocasiones. En este contexto, la alianza franco-rusa, aunque fuera dirigida únicamente contra Alemania, podía inquietar al Gobierno británico si la solidaridad de las dos potencias se afirmaba y se manifestaba fuera de Europa. Londres podía temer movimientos franceses en el valle del Nilo y movimientos rusos en el golfo de Petchili, en los límites meridionales del Turquestán y en los Estrechos turcos.

Por otro lado, a los cambios que se estaban produciendo en la posición industrial y comercial de Inglaterra se unían los que afectaban a la posición de la flota desde que los barcos de madera habían comenzado a ser reemplazados por los acorazados. Se necesitaba mucho tiempo para construir un barco de madera pero, después, ese barco duraba sesenta años; con la invención de la nueva y cada vez mas poderosa artillería, y con el desarrollo del blindaje capaz de resistirla, los barcos se hacen viejos en una generación. A finales de los años ochenta, el gobierno británico empiezó a considerar la posibilidad de que Rusia y Francia pudieran combinar sus flotas en el Mediterráneo y, con ello, poner en peligro la posición británica; la adopción de la regla del two Powers standard parecio garantizar el mantenimiento de la supremacía naval ${ }^{8}$. Pero, para la Inglaterra de finales del siglo $\mathrm{xIX}$, la cuestión fundamental es mas compleja; no se trata sólo de mantener la supremacía naval sobre la posible conjunción de las flotas francesa y rusa; lo importante para el futuro es que se estaba produciendo un cambio geopolítico que perjudicaba a las potencias navales, a aquellas potencias que, como Inglaterra, habían sido capaces de dominar los asuntos mundiales en una proporción que nada tenía que ver con el volumen de su población y territorio. A finales del siglo $\mathrm{xIX}$, todo - la industrialización, las inversiones, la nueva agricultura y las nuevas tecnologías - estaba modificando de manera inexorable el equilibrio de poder favoreciendo a los Estado-continente como Estados Unidos, Rusia y, posiblemente, Alemania. En esas nuevas circunstancias, ¿podría una isla competir con Estados de tan extensos territorios y tal volumen de población?

8 Marder, Arthur J.: British Naval Policy 1880-1905. The Anathomy of British Sea Power, Londres, Putnam \& Company, 1940. 
Las implicaciones diplomáticas del cambio de posición económica de Inglaterra a finales del siglo XIX fueron tenidas en cuenta por la mayor parte de sus dirigentes. Inglaterra estaba en el centro de un sistema global de intercambios y nada podía haber mas peligroso para ese centro que la interrupción del comercio por incertidumbres políticas o por una guerra. Por tanto, el Gobierno británico tenderá a considerar que la guerra era mala para los negocios y que la esencia de la diplomacia era asegurar los intereses del país sin recurrir a conflictos a gran escala; esta idea se mantendrá a pesar del aumento de competidores y de la condensación de conflictos coloniales que manifiestan los últimos años del siglo xix. Pero la pérdida de su posición privilegiada en ultramar tenía que afectar a Inglaterra; los estrategas se alarmaban cuando los competidores adquirían territorios cercanos a sus bases y rutas; los misioneros se resistían a dar por terminadas sus actividades en territorios que pasaban a otras manos; los círculos de negocios se inquietaban cuando veían imponer tarifas metropolitanas en territorios en los que comerciaban libremente. Todo este conjunto de impresiones se interiorizará y expresará a través de un fuerte incremento del sentimiento imperial, de una reacción masiva que valora cada vez mas un conjunto de colonias que todos parecen ambicionar. Conviene no perder de vista la ironía que encierra el hecho de que el orgullo imperial de estos años fuera esencialmente defensivo, que fuera realmente una expresión de debilidad, no de fuerza. Pues bien, la euforia imperial y la voluntad de poder que caracteriza a la Inglaterra de la última década del siglo XIX se manifestará políticamente a través de la victoria electoral, en 1895, de los conservadores del marqués de Salisbury y de los unionistas de Joseph Chamberlain. Pero ni la euforia imperial ni la voluntad de poder que acompañan a la formación del último Gobierno Salisbury, deben impedirnos tener muy presente que tanto el premier como su Gabinete eran muy conscientes de que la realidad sobre la que tenían que operar era realmente nueva: se estaba forjando una alianza franco-rusa que podfa actuar en el Mediterráneo Occidental y en el Pacífico, Estados Unidos se estaba desentumeciendo en el hemisferio occidental, el Imperio Otomano se estaba descomponiendo, el Reich alemán se estaba embarcando en una politica mundial y el transiberiano estaba listo para acercar tropas rusas a India y China.

Es en este contexto de una Inglaterra a la defensiva donde debemos colocar la aparición de lo que será un importante elemento de la nueva situación internacional: el progresivo acercamiento de Inglaterra a los Estados Unidos de América. La naturaleza de la relación anglo-norteamericana ha cambiado tanto a lo largo del siglo $\mathrm{xX}$, que es difícil entender su situación en la última década del siglo XIx. Por un lado, para la generación de Salisbury, Estados Unidos había contado poco en los asuntos internacionales: su crecimiento industrial no dominaba en Europa, sus políticos habían seguido los consejos de los padres fundadores y habían evitado alianzas, no tenían ni los medios y ni los deseos de intervenir fuera de su hemisferio y los norteamericanos aparecían ante los ojos de los británicos de más edad como gentes pacíficas y pro-

Hispania, LVII/2, núm. 196 (1997) 515-549 
vincianas. Sin embargo, por otra parte, esta minusvaloración británica del potencial norteamericano no había impedido que se fuera instalando, tanto en Inglaterra como en Estados Unidos, un fuerte sentimiento de hermandad que convertía la posibilidad de una guerra entre ellos en la rechazable hipótesis de una guerra fratricida y que fundamentaba la idea, que expresa como nadie Joseph Chamberlain, de que debería existir una relación especial entre las dos naciones anglosajonas.

Sin duda, la crisis, en el verano de 1895, por la delimitación de la frontera entre Venezuela y la Guayana británica, supondrá un gran sobresalto. La intervención abierta del Gobierno de los Estados Unidos en el viejo pleito fronterizo, que culminó con la proclamación formal del presidente Cleveland -en un mensaje a las Cámaras- del valor jurídico-normativo de la doctrina Monroe y de la responsabilidad que le correspondía al exigir que ambas partes se sometieran a una commisión de arbitraje en la que participasen juristas norteamericanos, tuvo efectos de un belicismo anti-británico absolutamente insospechado. El comportamiento de los Estados Unidos en esta crisis con Inglaterra - lo mismo que en la posterior con España- sólo se termina de entender si tenemos en cuenta ciertos elementos de su cultura política: convencidos de que su sistema de gobierno era moralmente superior a la monarquía y de que la democracia republicana podía proporcionar la felicidad a los habitantes del hemisferio americano, la apelación de Cleveland en 1896 a la doctrina Monroe expresaba su fé en que los pueblos que vivían en América marchaban hacia un futuro dorado si se mantenían dueños de sí mismos impidiendo la intervención de las potencias europeas en sus asuntos. El Gobierno de Salisbury contuvo la ira y sè mantuvo frío; pensó en las consecuencias de una guerra entre dos pueblos unidos por la sangre, la cultura y el comercio; pensó en el cúmulo de problemas a los que Inglaterra tenía que hacer frente en aquellos momentos y apaciguó el conflicto: facilitó los documentos que la comisión mediadora le pidió y ordenó a su embajador en Washington que siguiese las recomendaciones de la comisión y negociase con Venezuela. En cualquier caso, no debemos olvidar que, en los años 1896-1898, el Gobierno de Salisbury estaba empeñado en un esfuerzo muy consciente para mejorar sus relaciones con los Estados Unidos, no sólo para servir a la hermandad entre los dos pueblos, sino también, y sobre todo, para conseguir su apoyo diplomático en Asia Oriental, la zona estratégica en la que los intereses británicos estaban corriendo los mayores riesgos ${ }^{9}$.

9 Sobre el planteammiento general de la política exterior de Salisbury, véase GrENVILLE, J. A. S.: Lord Salisbury and Foreign Policy. The Close of the Nineteenth Century. Londres, 1964, y Howard, Christopher D.: Splendid isolation: a study of ideas concerning Britain's international position and foreign policy during the later years of the Third Marquis of Salisbury. Londres, 1967. Sobre las relaciones anglo-norteamericanas antes y después de 1898, véase CAMPBELL Jr., Charles S.: Anglo-American Understanding. Baltimore, 1957; CAMPBELL, A. E.: Great Britain and the United States 1895-1903. Londres, 1960; MAY, Ernest R.: Imperial Democracy. The Energence of America as a Great Power. Nueva York, 1961, y NEALE, R. G.: Great Britain and United States Expansion I898-1900. Michigan University Press, 1966. 


\section{ESPAÑA, INGLATERRA Y EL NUEVO CONTEXTO INTERNACIONAL}

A mi juicio, el punto de inflexión de las relaciones hispano-británicas en la nueva situación internacional de los noventa tiene que ver con la ruptura del statu quo del Mediterráneo Occidental, con la seguridad de Gibraltar y con el nuevo valor que, para Inglaterra, podría tener la amistad o enemistad de España. En concreto, la coincidencia de la necesidad británica de ampliar el puerto de Gibraltar, para dar cabida a barcos cada vez mas grandes, con los avances de la artillería pesada que podría colocarse en sus inmediaciones y con la nueva situación creada en el Mediterráneo como consecuencia de la alianza franco-rusa, llevó al Gobiemo británico a declaraciones solemnes señalando que la posesión completa y segura de Gibraltar, que siempre había sido necesaria para hacer posible la conjunción entre las flotas del Canal y del Mediterráneo, lo era ahora todavía mas como consecuencia de la «moral junction" que habia tenido lugar entre las flotas de Cronstadt y de Toulon ${ }^{10}$. Sobre esta base, el Foreign Office se mostró muy interesado en febrero de 1894 por las noticias aparecidas el día 13 en Le Temps de París sobre una supuesta decisión del Gobierno español de fortificar algunas posiciones cercanas a la bahía de Algeciras. El Ministerio de Exteriores, el embajador en Madrid, el secretario de Colonias, el gobernador de Gibraltar, el Almirantazgo y su División de Inteligencia, intercambiaron una nutrida correspondencia entre el 17 de febrero y el 7 de abril con la intención de indagar en la noticia y de valorar sus consecuencias a corto y medio plazo ${ }^{11}$. Después de llegar al convencimiento de que la noticia del periódico francés sobre la construcción de fortificaciones para artillería pesada en Sierra Carbonera era cierta, aunque la realización completa del proyecto no fuera inmediata, la correspondencia entre los distintos organismos del Gobiemo británico se centró en el análisis de la distancia que podía cubrir la nueva artillería en relación con la distancia entre el puerto y los puntos mas altos y cercanos de la bahía de Algeciras.

Segismundo Moret, en ese momento en la oposición, consideró, por su parte, que aunque la cuestión de Gibraltar fuera para España una cuestión de "patriotismo teórico», la nueva situación del Mediterráneo - tras la visita a Francia de la escuadra rusa, los incidentes en Marruecos y los debates de la Cámara de los Lores sobre la seguridad de Gibraltar- exigía del Gobierno español medidas para proteger el comercio en la zona y para reforzar la seguridad del Estrecho; en cualquier caso, Moret sugería la necesidad de buscar un acercamiento hispano-británico que, adelantándose a futuras complicaciones europeas, fortaleciese a Gibraltar sin que los británicos sintieran la

10 Public Record Office, Kew, Richmond, Inglaterra (PRO). Correspondencia del Foreign Office (FO). Impresos confidenciales, 425 , vol. 219 , documento 50. Declaración del primer ministro británico en la Cámara de los Lores, Londres, 20 diciembre 1893.

II PRO/FO425/222. Documentos 13-27.

Hispania, LVIL/2, núm. 196 (1997) 51\$-549 
necesidad de buscar ese fortalecimiento en la ampliación de los límites de la plaza ${ }^{12}$.

A la vista de las declaraciones de Moret - y de las que El Imparcial había recogido de Gamazo y del Marqués de la Vega de Armijo-, el embajador británico resumía sus impresiones señalando el cambio que había supuesto para la posición internacional de España «la asunción por Rusia de una parte directa en la política mediterránea», un cambio que el embajador percibía como la causa del nuevo tono de la prensa y de los políticos españoles, que le parecían convencidos de que la necesidad de fortalecer Gibraltar debía llevar a los británicos a sentir que necesitaban la amistad de España; en particular el embajador se mostraba convencido de que Moret era sincero cuando consideraba que, en la nueva situación, Gibraltar podría ser «una lazo de amistad" que podría permitir a España contar con una alianza británica que le protegiera "frente a los designios de los otros" y que le permitiera "mantenerse independiente de Francia en asuntos comerciales y financieros» ${ }^{13}$.

Por su parte, el Almirantazgo señalaba al Foreign Office los contornos del problema que podría plantearse en el futuro si España colocaba baterías de artillería pesada en Sierra Carbonera: mientras que se tratase sólo de España, no consideraban que existiera causa de inquietud, pero en la eventualidad de una guerra con Francia en la que España fuera su aliada, y a la vista de los cálculos realizados, los marinos consideraban que la posición de Gibraltar podría ser dificil. Teniendo en cuenta que la flota francesa se encontraría en Toulon y que, para mantener su posición en el Mediterráneo, la flota británica tendría que concentrarse en Gibraltar, convendría considerar si los planes militares británicos debían incluir en el futuro la posibilidad de ocupar Sierra Carbonera en caso de inicio de hostilidades con Francia; si fuera posible asegurar la neutralidad española -seguía explicando el Almirantazgo-, la cuestión no se plantearía, pero si la amistad España fuera dudosa, sería necesario actuar a tiempo ${ }^{14}$.

Como el riesgo no parecía inminente, los informes se guardaron en los archivos y en la memoria de los hombres del Almirantazgo y del Foreign Office donde permanecerán hasta el momento en el que la crisis de Fachoda del verano/otoño de 1898 y el riesgo de una guerra franco-británica en el Mediterráneo obligue a la Navy a actualizarlos y a volverlos a poner sobre la mesa ${ }^{15}$. Mientras tanto, Inglaterra seguirá con atención todas las cuestiones que afec-

12 PRO/FO425/222. Documento 21: Sir Henry Drummond Wolff al conde de Kimberley, ministro británico de Asuntos Exteriores, Madrid, 14 marzo 1894, despacho 85, secreto y confidencial.

${ }_{13}$ PRO/FO425/222. Documento 26: Wolff a Kimberley, Madrid, 30 marzo 1894, despacho 112, secreto y confidencial.

14 PRO/FO425/222. Documento 25: Almirantazgo a Foreign Office, Londres 31 marzo 1894, confidencial.

Is JOVER ZAMORA, José María: "Gibraltar en la crisis internacional del 98», en: Política, diplomacia y humanismo popular en la España del siglo XIX, Madrid, Turner, 1976, págs. 431-488. DE LA TORRE DEL Rio, Rosario: «Gibraltar y el planteamiento del problema de la garantía exterior», capítilo 8 de Inglaterra y España en 1898, Madrid, EUDEMA, 1988, págs. 249-292; y «La crisis de 1898 y el problema de la garantía exterior», en: Hispania, Centro de Estudios Históricos (CSIC), Madrid, t. XLVI (1986), págs. 115-164. 
taban a la seguridad de sus intereses en el Mediterráneo y mantendrá, mientras le sea posible, los acuerdos que la ligaban con la Triple Alianza a traves de Italia; acuerdos, no lo olvidemos, a los que también estaba ligada España.

En efecto, el 4 de mayo de 1887, Moret, en ese momento ministro de Estado, y el embajador de Italia en Madrid, conde de Maffei, firmaron un acuerdo secreto que vinculó a España con la política de la Triple Alianza en general y con su estrategia - y la de Inglaterra- de aislar a Francia en particular. Desde que conocieron la existencia del Acuerdo, los conservadores españoles no dejaron de manifestar sus recelos ante la nueva vinculación. El Acuerdo de 1887, por cuatro años, fue renovado por otros cuatro en 1891, pero no se renov6́ en 1895. En ese momento estaban en juego las relaciones comerciales de España con los miembros de la Triple Alianza, y Roma y Berlín entenderán que la actitud española respecto a las negociaciones comerciales era una muestra clara de su inclinación progresiva hacía Francia. El ministro italiano exigió a España, que en principio estaba dispuesta a renovar los Acuerdos en los mismos términos que en 1891, una garantía clara de que en ningún caso se acercaría a Francia, una garantía que se planté en términos de hacer público el Acuerdo renovado que era, no lo olvidemos, anti-francés. Moret no aceptó los planteamientos italianos y el duque de Tetuán, ministro desde marzo de 1895, tampoco. Transcurrieron los meses, pasó el 4 de mayo y con esta fecha dejó de estar en vigor el Acuerdo hispano-italiano; Roma y Madrid siguieron negociando y el 8 de octubre Tetuán envió al embajador de España en Roma unas instrucciones que no dejan lugar a dudas sobre la posición del gobierno conservador español: el ministro consideraba que, a aquellas alturas, las relaciones con Francia y con Inglaterra iban siendo progresivamente mas cordiales (Francia había abierto la Bolsa de París a la contratación de los billetes hipotecarios de Cuba en una cantidad superior a 150 millones de pesetas) y que el Acuerdo con la Triple parecía innecesario; no había servido para evitar los problemas comerciales con Alemania y no parecía necesario para entenderse con Inglaterra mientras que, por el contrario, de renovarse, Francia podría tomar represalias cerrando su mercado financiero y alentando a los republicanos; España debía desligarse de la Triple sin brusquedades, reiterando su amistad y su decision de no participar en ninguna otra coalicion internacional ${ }^{16}$.

\section{EN BUSCA DE UNA GARANTÍ INTERNACIONAL PARA CUBA}

El 24 de febrero de 1895 se reanudó la insurrección en Cuba. El levantamiento, que tuvo su primer foco en el este, se extendió con relativa facilidad $\mathrm{y}$, antes de que la insurrección cumpliera un año, los rebeldes estaban

16 Garcia SANZ, Fernando: Historia de las relaciones entre España e ltalia. Imágenes, comercio y política exterior (1890-1914). Madrid, CSIC, 1993, págs. 47-83. SALOM COSTA, Julio: «Del

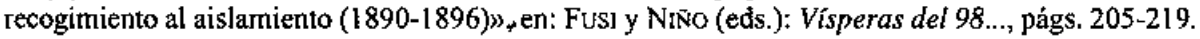

Hispania, LVI1/2, nüm. 196 (1997) 515-549 
luchando en las cercanías de La Habana, destruyendo a su paso plantaciones y comunicaciones. La insurrección, y las dificultades para atajarla de manera inmediata, provocaron la caída del tercer Gobierno Sagasta que fue sustituido por el sexto Gobierno Cánovas en marzo de 1895. De manera inmediata, el general Martínez Campos fue enviado a la isla para ponerse al frente de los esfuerzos militares del nuevo Gobierno conservador. En enero de 1896, la dimisión del Gobernador General dejaba constancia de que estos esfuerzos no habían teniendo ningún exito. Las dificultades del Gobierno español colocaron a los Gobiernos de las grandes potencias europeas en la situación de tener que considerar que la vuelta a la normalidad en Cuba iba a ser una cuestión de muchos mas hombres, de mucho mas dinero, de mucho mas tiempo y en la que el Gobierno de los Estados Unidos, con intereses en la isla que la guerra perjudicaba claramente, podría intervenir. En efecto, ninguna potencia ignoraba que, desde comienzos de 1896, los norteamericanos, a través de la Legación de España en Washington, venían animando de manera informal al Gobierno de Madrid para que realizase reformas y para que contase con su ayuda para pacificar la isla ${ }^{17}$.

Desde el mismo momento en que se planteó la evidencia de la creciente y peligrosa intervención norteamericana en el conflicto cubano, la diplomacia española se orientará en una dirección que no abandonará ni siquiera cuando estalle la guerra con los Estados Unidos: primero intentará conseguir una garantía internacional formal para la continuidad de la soberanía de España en Cuba, después, ante la evidencia de que no era posible, los Gobiernos de Cánovas y de Sagasta intentarán concitar una acción colectiva de las grandes potencias europeas bajo la dirección de Inglaterra para evitar la intervención norteamericana primero, para limitar los costes de la derrota después.

Para entender bien el papel jugado por la diplomacia británica en la negociación multilateral abierta por el gobierno Cánovas en busca de una garantía exterior para los intereses españoles en Cuba, para entender bien las diferencias que aparecieron entre la contención y el mutismo del Gobierno de Londres y la simpatta y actividad del embajador británico en Madrid, es preciso, a mi juicio, no perder nunca de vista que las iniciativas diplomáticas españolas - tanto las del Gobierno Cánovas como las del Gobierno Sagastacontarán con un aliado insospechado: el embajador británico en Madrid, sir Henry Drummond Wolff ${ }^{18}$. En efecto, la correspondencia, tanto oficial como

17 OfFNER, John L.: An Unwanted War. The Diplomacy of the United States and Spain over Cuba, 1895-1898. Londres, The University of North Carolina Press, 1992.

18 Henry Drummond Charles Wolff nació el 12 de octubre de 1830, se educó en la isla de Malta y en 1846 ingresó en el servicio diplomático británico; en 1852 fue destinado a la Embajada de Florencia, en 1855 fue enviado a Egipto con el objeto de redactar un proyecto de constitución para ese país y en 1856 fue destinado a la Embajada de Bruselas; secretario particular del ministro de Asuntos Exteriores conde Malmesbury en febrero de 1858 y del ministro de Colonias sir Bulver Lytton en noviembre de ese mismo año, desde 1859 a 1864 fue secretario del gobernador de la islas Jónicas; en 1874 fue elegido miembro de la Cámara de los Comunes, desde 1880 dentro del Fourth Parry presidido por lord Randolph Churchill y por él, mismo. Cuando lord Salisbury volvió al 
particular, entre el embajador Wolff y el marqués de Salisbury, premier y ministro de Asuntos Exteriores del Reino Unido a lo largo de los años 18961898 muestra los esfuerzos del embajador británico por empujar a su Gobierno en favor de España. Su cariño y admiración hacia la Reina Regente, su solicitud por el destino de la Dinastía, su alta valoración de los intereses británicos en el Mediterráneo, consolidados por su experiencia política y diplomática en zonas donde el Imperio Británico se enfrentaba al Imperio Ruso, su percepción de los peligros que se derivaban para los intereses británicos de la reciente alianza del Imperio Ruso con la República Francesa, su conocimiento de los planteamientos que se venían haciendo sobre la seguridad de Gibraltar y su creencia en el valor de España como aliado mediterráneo de Inglaterra, llevarán al embajador, que mantendrá siempre una relación muy amistosa y confiada con Segismundo Moret, a entrevistarse una y otra vez con los embajadores de las otras potencias en Madrid, dando la sensación de un interés británico por los problemas españoles que era exclusivamente suyo, a bombardear al Foreign Office con una serie de telegramas y despachos en los que va desgranando sus múltiples conversaciones con unos y otros y en los que va resaltando en cada momento los argumentos que, a la vista de las siempre lacónicas respuestas de Salisbury, considera que mejor pueden convencer a premier y a intentar organizar una entrevista, en San Sebastián, entre la Reina Regente y Salisbury. Todos los esfuerzos de Wolff se fueron estrellando contra la firme posición de un premier que tenía una idea muy estricta de su propia posición: la orientación de la política exterior británica la formulaba él, y de esa formulación era responsable ante el Parlamento; de sus subordinados esperaba información, no consejos. Sobre esta base, frente a su percepción de la importancia de la amenaza rusa a la libertad de comercio en Asia Oriental, el destino de las colonias españolas se le aparecía como un asunto verdaderamente menor. Sus intentos para persuadir a los Estados Unidos de que se colocaran junto a Inglaterra para frenar futuros avances de Rusia en el Pacífico, en una dirección muy peligrosa para intereses funda-

gobierno en junio de 1885 fue nombrado consejero privado y en agosto fue enviado en misión oficial a Constantinopla para discutir con el gobierno turco el futuro de Egipto, militarmente ocupado por los británicos desde 1882. En 1887 fue nombrado enviado especial en Persia y, desde ese puesto puso en marcha una iniciativa para buscar un acuerdo con Rusia sobre el viejo imperio asiático. Una grave enfermedad paralizó sus proyectos y le obligó a regresar a Inglaterrạ. Tras una breve missión no querida en Bucarest, a comienzos de I892 fue nombrado embajador en España, donde permanecerá hasta su excedencia en 1900; murió en Brighton el 11 de octubre de 1908. Aunque la carrera diplomática de Wolff aparezca vinculada fundamentalmente con la cuestión de Oriente, su vinculación sentimental con España es muy anterior a su experiencia como embajador; en 1851, tras un viaje por nuestro país, escribió un libro titulado Madrilenia; or, Pictures of Spanish Life que recoge sus impresiones. Pero ni este libro, ni los demás que escribió a lo largo de su vida, entre ellos algunos de memorias - Some notes of the past, 1870-1891 (Londres, 1893) y Rambling recollections (Londres, 1908) - nos sirven para documentar sus opiniones políticas. En el Dictionary of National Biography. Twentieth Century 1901-191/ publicado por Spottiswoode \& Co. en 1912 y reeditado por Oxford University Press en 1976 se eneuentra un largo artículo dedicado al personaje.

Hi.spania. LVIL/2, núm. 196 (1997) 515-549 
mentales británicos, no quedarán comprometidos por ningún gesto a favor de España después de haber soportado estoicamente, a finales de 1895 y principios de 1896, la intempestiva intromisión de la doctrina Monroe en el litigio de la frontera entre Venezuela y la Guayana Británica ${ }^{19}$.

La que podríamos considerar la batalla personal de Wolff, se inició a comienzos de 1896. Mientras los embajadores y los ministros de Exteriores de todas las potencias intercambiaban información sobre los rumores de un acercamiento alemán a Francia y a Rusia, acercamiento que, además de explicar el fracaso de la renovación de los Acuerdos Mediterráneos a comienzos de 1895, significaría un aislamiento mayor del Reino Unido ${ }^{20}$, el embajador británico en Madrid empezó a bombardear al Foreign Office con una serie de despachos en los que transmitía información sobre un posible acercamiento entre España y Francia; el embajador señalaba que aunque la opinión general de los políticos españoles fuera que Inglaterra, como poder marítimo, sería un mejor aliado para España, las dificultades económicas creadas por la guerra de Cuba, podrían llevar a la Regente a propiciar una alianza pública con Francia a cambio de su apoyo financiero 21 . Para una diplomacia siempre atenta a la seguridad de Gibraltar y que en febrero-abril de 1894 había tenido ocasión de establecer con claridad los riesgos de un acercamiento hispanofrancés en la nueva coyuntura creada en el Mediterráneo Occidental por la alianza franco-rusa, la primera indicación de su embajador en Madrid el 26 de febrero no pasó desapercibida. Al día siguiente el premier pidió mas información ${ }^{22}$ y entonces el embajador se extendió sobre sus conversaciones al respecto con los embajadores alemán e italiano y puso en boca de este último la información de que en las conversaciones hispano-francesas se había hablado de Gibraltar ${ }^{23}$. Ese mismo día 27 de febrero, el embajador británico telegrafió a última hora de la tarde sus impresiones de la visita que acaba de recibir de Segismundo Moret: el político liberal se mostraba muy alarmado ante la idea de una alianza hispano-francesa y consideraba posible que el Gobierno Cánovas pudiese aceptarla si el Gobierno francés facilitaba la colocación en la Bolsa de París de los millones de francos que España necesitaba para convertir su deuda y equilibrar sus finanzas ${ }^{24}$. Al día siguiente, Wolff en un nuevo telegrama trasmitía lo que no podía ser entendido mas que como la

19 Neale, R. G.: «Diplomatic Prelude», capítulo I de Great Britain and United States Expansion: 1898-1900, Michigan State University Press, 1966, págs. 1-42. Para la cuestión que nos ocupa, este libro tiene la ventaja de incorporar la consulta de la correspondeneia particular Wolff-Salisbury archivada en los Papers of Third Marquis of Salisbury depositados en la Biblioteca del Christchurch College de Oxford.

20 PRO/FO72 (correspondencia general con España)/2003. Wolff al marqués de Salisbury, primer ministro y ministro de Astuntos Exteriores del Reino Unido, Madrid, 16 febrero 1896, despacho 34 , secreto y confidencial.

21 PRO/FO72/2006, Wolff a Salisbury, Madrid, 26 febrero 1896, telegrama 21, muy secreto.

22 Ibidem. Salisbury a Wolff, Londres, 27 febrero 1896, telegrama 6, secreto.

23 Ibidem. Wolff a Salisbury, Madrid, 27 febrero 1896, telegrama 22, muy secreto.

24 Ibidem. Wolff a Salisbury, Madrid, 27 febrero 1896, telegrama 23, muy secreto. 
segunda parte de su conversación con Moret: «un muy conocido político» le había sugerido, "de manera privada», la idea de una «mediación anglo-norteamericana" entre España y los rebeldes cubanos; España temía que los Estados Unidos terminasen reconociendo la beligerancia de los rebeldes y la mediación podría aflojar la tensión financiera y facilitar la búsqueda de un status satisfactorio para la Isla ${ }^{25}$. El Foreign Office no tardó en responder a su embajador: la cuestión era muy difícil, Estados Unidos no aceptaba mediaciones de ese tipo de potencias europeas ${ }^{26}$. En los días siguientes, mientras se desinflaban las noticias sobre una inminente alianza hispano-francesa ${ }^{27}$, el Gobierno español, que estaba pendiente de lo que el Senado norteamericano pudiera decidir sobre el reconocimiento de la beligerancia de los insurrectos, llevó este asunto ante las potencias y pidió asistencia diplomática para evitarlo ${ }^{28}$. El día 1 de marzo, Cánovas habló con el embajador británico de la cuestión y el presidente del Consejo aprovechó la ocasión para afirmar que deseaba actuar con Inglaterra en la cuestión de Marruecos y que sus entrevistas con el embajador francés se habían limitado a asuntos financieros ${ }^{29}$.

El fracaso del general Martínez Campos, el nombramiento del general Weyler, la brutalidad de sus medidas y la falta de un horizonte de conclusión de un conflicto que les perjudicaba claramente, llevaron a los Estados Unidos a pasar de los ofrecimientos oficiosos de mediación a la concreción que supuso la Nota de 10 de abril de $1896^{30}$. Diez días después, el embajador británico en Madrid comunicaba al Foreign Office que el nuevo Gobierno italiano salido de la crisis de Adua había propuesto a España, a través de su embajador en Roma, una nueva negociación para renovar los Acuerdos Mediterráneos y que el duque de Tetuán consideraba que las complicaciones cubanas hacían difícil su aceptación ${ }^{31}$. El 23 de abril, el embajador podía informar con mas detalle de la propuesta del conde Nigra, sostenida por la diplomacia austriaca, asi como de la inmediata respuesta del duque de Tetuán: la guerra de Cuba había alterado la situación y no deseaba ofender a Francia a menos que obtuviera apoyo explícito en la cuestión cubana ${ }^{32}$. En sus informes al Foreign Office, el embajador Wolff volvió a plantear la posibilidad de un acercamiento hispano-británico: el duque de Tetuán le habría señalado, «sin precisiones», su deseo en ese sentido sobre la base de lo que para el ministro -posible-

25 PRO/FO72/2024. Wolff a Salisbury, Madrid, 28 febrero 1896, telegrama 24, muy secreto.

26 Ibidem. Minuta affadida al telegrama con texto de T.H. Sanderson, subsecretario permanente del Foreign Office y órdenes de Salisbury de responder a Wolff en el sentido señalado.

27 PRO/FO72/2006. Wolff a Salisbury, Madrid, 29 febrero 1896, telegrama 25, muy secreto.

28 PRO/FO72/2024. Wolff a Salisbury, Madrid, 29 febrero 1896, telegrama 26. Minuta de Salisbury ordenando remitir el texto al embajador británico en Washington.

29 Ibidem. Wolff a Salisbury, Madrid, 2 marzo 1896, telegrama 28, muy secreto. Minuta de Salisbury ordenando el envio del texto al embajador británico en Washington.

30 Libro Rojo. Volumen IV, núm. 19, documento 1, ministro plenipotenciario de España en Washington a Ministro español de Estado, Washington, 10 abril 1896, págs. $1-8$.

31 PRO/FO72/2006. Wolff a Salisbury, Madrid, 20 abril 1896, telegrama 49.

32 PRO/FO72/2003. Wolff a Salisbury, Madrid, 23 abril 1896, despacho 89, muy secreto.

Hispania, LVI1/2, núm. 196 (1997) 515-549 
mente también para el embajador-era la fuerza principal de España: su posición geográfica. Con puertos en el Atlántico, en el Estrecho y en el Mediterráneo, España podría ofrecer "grandes beneficios» a la flota británica en el caso de que una guerra afectase a esas áreas; el acceso de los barcos británicos a esos puertos y a Gibraltar podría quedar asegurado con el empleo de tropas españolas en los Pirineos sin que Francia pudiese contar con una ruta terrestre para atacar Gibraltar; en caso de sitio naval, España podría ser un refugio para la población civil de la plaza; además, España podría cooperar con Inglaterra en Marruecos y, en cualquier caso, se evitaría un "peligroso" acercamiento hispano-francés ${ }^{33}$. Aunque no se planteara de manera oficial, es indudable, a mi juicio, que la iniciativa española — tanto de Moret como de Tetuán- ligaba la garantía internacional de Cuba con la posibilidad de una alianza hispano-británica que fortaleciese el Gibraltar británico.

En los días siguientes la posición española se va afirmando: teniendo en cuenta la situación creada por la guerra de Cuba, el duque de Tetuán quería «apoyo frente a las pretensiones de los Estados Unidos» y se uniría a la Triple Alianza y a Inglaterra, incluso de manera pública, si las potencias concernidas apoyaban a España en la cuestión cubana. En este contexto, el embajador Wolff trasmitió al marqués de Salisbury el deseo de Tetuán de contar con el consejo del premier británico ${ }^{34}$. Para un país tenido tradicionalmente por orgulloso, la petición de consejo a un gobierno extranjero no deja de ser un cuestión de interés, sobre todo si no era sólo el ministro de Estado el que pedía consejo al primer ministro británico, si también la Reina Regente se dirigía por las mismas fechas a la Reina Victoria con la misma intención. En efecto, en el mes de mayo, la Regente escribió a la Reina de Inglaterra una carta en la que después de lamentar la situación crítica en la que la guerra de Cuba había colocado a España, señalaba la «actitud dudosa» de los Estados Unidos: mientras su Gobierno prometía neutralidad y amistad, sus ciudadanos enviaban dinero, armas y municiones a los insurgentes; el presidente Cleveland recomendaba hacer "concesiones inmediatas" a los rebeldes para obtener la paz, pero la Regente consideraba que no podía hacer concesiones hasta que los rebeldes no dejasen las armas; Cleveland se ofrecía como mediador pero esa mediación "heriría el sentimiento nacional de los españoles» y doña María Cristina afirmaba que no podría aceptarlo nunca sabiendo que Estados Unidos «trabajan en favor de los insurgentes»; finalmente la Regente pedía a la Reina de Inglaterra "me asista en estas circunstancias con su consejo y amisad" ${ }^{35}$.

33 Ibidem. Wolff a Salisbury, Madrid, 24 abril 1896, despacho 90, secreto y confidencial.

34 Ibidem. Wolff a Salisbury, Madrid, 26 abril 1896, despacho 98, muy secreto.

35 No he visto el original de ninguna de las cartas que la Reina Regente de Espanta envió a la Reina de Inglaterra -imagino que todas ellas en francés- y que cito en este trabajo. Todas ellas las traduzco de la transcripción al inglés que aparece publicada en: The Letters of Queen Victoria. Third Series. A Selection from her Majesty's Correspondence and Joumal beetwen the Years 1886 and 1901, editadas por George Earle Buckle. Londres, Murray \& Co., vol. Ill (1896-1901), 1932. Carta de la Reina María Cristina a la Reina Victoria, la transcripción de esta carta aparece sin fecha precisa, exclusivamente con la referencia «may 1898», págs. 44-45. 
Como cuando la correspondencia particular de la reina Victoria afectaba a cuestiones políticas, la respuesta de la soberana británica reproducía con toda precisión el parecer de su primer ministro, al que enviaba de manera inmediata copia de la carta recibida, la posición de Salisbury en relación con las iniciativas españolas está especialmente bien documentada. El 25 de mayo, tres días antes de contestar a la petición de consejo que le había enviado el duque de Tetuán, envió a la reina Victoria el esquema de la contestación que debía transmitirse a la Reina Regente española:

«... después de la expresión de profunda simpatía, Vuestra Majestad podría contestar que a su juicio poco bueno puede venir del anuncio de concesiones hasta que la revolución en Cuba quede suprimida o al menos hasta que una victoria importante se haya ganado. Reformas anunciadas antes de que los rebeldes hayan sido derrotados podría no inducirles a dejar las armas. Podrían simplemente verse animados a insistir en la independencia completa. Estados Unidos hará todo el daño que pueda sin entrar en la guerra. Existe en Inglaterra una gran simpatía hacia España; pero, por supuesto, Inglaterra no puede colaborar en la supresión de la insurrección. (Inglaterra) se alegraría de poder proporcionar cualquier asistencia que fuera posible sin romper la neutralidad» ${ }^{36}$.

El consejo a la Regente se completó tres días después, el 28 de mayo, con la respuesta que Salisbury envió al duque de Tetuán a través del embajador Wolff. Si exceptuamos algún telegrama para pedir más información sobre la posible negociación hispano-francesa, Salisbury no había contestado a ninguna de las comunicaciones que le venía enviando su embajador en Madrid; por esta razón, este despacho tiene, a mi entender, una gran importancia porque, mas allá de posibles consejos, fija, ante la primera iniciativa española para articular una acción de las potencias europeas para frenar a Estados Unidos en Cuba, la posición del Gobierno británico sobre las mismas bases que mantendrá a lo largo de todo el 98: Salisbury, que no hace la menor referencia a la sugerencia de un acuerdo hispano-británico para asegurar Gibraltar, empezaba explicando su falta de respuesta: aunque deseaba la paz entre España y los cubanos, consideraba que no se daban las circunstancias que hicieran conveniente una acción británica y, para prevenir cualquier malentendido, rompia el silencio y hacía llegar al embajador sus instrucciones: el Gobierno británico no deseaba intervenir en el conflicto y debía evitar cualquier declaración que pudiera animar a alguien a pensar que Inglaterra podría cambiar de opinión. Este planteamiento no significaba que no sintiera la más profunda simpatía por una España en dificultades; Inglaterra estaba interesada en que España fuera próspera y fuerte y debía lamentar cualquier calamidad que detuviera su progreso; como la separación de Cuba sería un serio golpe para su posición internacional, Salisbury se mostraba convencido de que el Gobierno de la Reina Regente utilizaria la primera oportunidad razonable que tuviera para garantizar a los habitantes de Cuba las medidas de

36 Ibidem, carta de Lord Salisbury a Reina Victoria, 25 mayo 1898, págs. 45.

Hispania, LVII/2, núm. 196 (1997) 515-549 
1895-1898: INGLATERRA Y LA BÚSQUEDA DE UN COMPROMISO JNTERNACIONAL 533

autonomía que pudieran asegurar el buen gobierno de la Isla. El premier terminaba su despacho autorizando a su embajador a que expresara al Gobierno español las simpatías de Londres hacia una política autonómica para Cuba y su disposición a utilizar sus buenos oficios si se consideraba que podía contribuir a una pacificación basada en la autonomía ${ }^{37}$.

Mientras el duque de Tetuán, enterado por Wolff del sentido general de las palabras de Salisbury, intentaba forzar la entrega de un texto escrito con el ofrecimiento de buenos oficios por parte del Gobierno británico, la diplomacia española continuaba con las exploraciones previas abiertas con la iniciativa italiana de renovar los Acuerdos Mediterráneos; en las semanas siguientes se mantendrán todos sus elementos fundamentales: los deseos italianos y austriacos de renovar los Acuerdos, la exigencia española de una garantía para Cuba, el interés alemán por mejorar las condiciones de su comercio con España y el desinterés británico. La correspondencia del embajador Wolff con el Foreign Office documenta con todo detalle los esfuerzos del embajador austriaco en Madrid, conde Dubsky, para convencerlo de la necesidad de renovar los Acuerdos Mediterráneos invocando unas veces los peligros del aislamiento británico y otras los peligros de la posición de la Reina Regente ${ }^{38}$.

El 8 de junio, Salisbury, ante el deseo de Cánovas de disponer por escrito de la posición británica expresada a través de Wolff, prorcionó a su embajador un pequeño texto con las instrucciones de leerlo en presencia del presidente español: Wolff debía limitarse a decir ante Cánovas que el Gobierno británico le pedía que le expresara los fuertes sentimientos de simpatía y amistad que sentía por España y sus deseos, siempre que fuera posible, de servir esos sentimientos cuando se formulasen propuestas concretas ${ }^{39}$. El valor operativo de esos sentimientos queda claro ante las rotundas palabras que el primer ministro británico pronuncia ante Henry White cuando, a lo largo de ese verano, el representante de los Estados Unidos en Londres le sondea sobre su actitud ante la cuestión cubana: "No es asunto nuestro; somos amigos de España y lamentariamos verla humillada, pero consideramos que no tenemos nada que decir en el asunto cualquiera que pueda ser el camino que Estados Unidos puedan seguir» ${ }^{40}$. Por supuesto el duque de Tetuán no conocerá estas palabras de Salisbury y, sobre la base de la expresión formal de los sentimientos amistosos de Inglaterra, del interés alemán en la renovación del Tratado comercial y del interés italiano y austriaco en la renovación de los Acuerdos Mediterráneos, preparará una estrategia para implicar a todas las grandes potencias europeas en una acción colectiva que detuviese las iniciativas norteamericanas en Cuba.

37 PRO/FO72/2025. Salisbury a Wolff, Londres, 28 mayo 1896, despacho 67, confidencial, borrador a máquina.

38 PRO/FO72/2004. Wolff a Salisbury, Madrid, 2 junio 1896, carta privada y secreta y 3 junio 1896, despacho 127.

39 PRO/FO72/2006. Tomas H. Sanderson, subsecretario permanente del Foreign Office, a Wolff, Londres, 8 junio 1896, telegrama y memorándum para ser leído.

40 Citado en Mowat, R. B.: The Life of Lord Pauncefote. Londres, 1929, pág. 204. 


\section{EL MEMORÁNDUM DE 1896}

El embajador británico, que fue informado por el duque de Tetuán de sus intenciones el 20 de junio ${ }^{41}$, conoció también el deseo alemán de buscar un acuerdo entre las potencias para defender el principio monárquico ${ }^{42}$. Salisbury no cambió su posición: no enviará instrucciones precisas hasta que no conozca la naturaleza de la propuesta en la que piensa el ministro español, pero considera que cualquier iniciativa colectiva debja ser recibida favorablemente por Rusia, que no tenía intereses directos en la cuestión y que estaba en buenos términos con Estados Unidos; en cualquier caso, el premier suponía que Estados Unidos rechazaría, por principio, cualquier propuesta para que actuase en concierto con las potencias europeas ${ }^{43}$.

El 3 de julio, el duque de Tetuán seguía insistiendo en que fuera Londres quien centralizase la acción de las potencias cuando comunica formalmente al embajador británico la ruptura de las exploraciones previas para negociar la renovación de los Acuerdos Mediterráneos y el sentido que tendrá la iniciativa que ha puesto en marcha para concitar la acción colectiva de las potencias: una intervención análoga a la que realizaron en 1852 los Gobiernos británico y francés y que ahora debería contar con el protagonismo de las seis grandes potencias ${ }^{44}$. Así, sin precisar la acción que se solicitaba, pero colocando como referencia una Nota que se correspondía con una situación internacional completamente distinta, pero en la que Inglaterra y Francia habían pedido formalmente a Estados Unidos que renunciara a la posesión de la Isla de Cuba, el duque de Tetuán intentó explorar hasta dónde estaban dispuestas a llegar las potencias antes de redactar su memorándum.

El Gobierno austro-húngaro, a través del embajador británico en Viena, hizo saber al Gobierno de Salisbury su buena disposición para participar en la acción colectiva que solicitase España, una acción colectiva que, por supuesto no podría dar a España la garantía de que seguiría en posesión de Cuba, pero que podría evitar la catástrofe que para el Trono de derivaría de una intervención norteamericana. La respuesta de Salisbury recomendaba prudencia a la hora de ofrecer buenos oficios a un Estado tan susceptible para estas cosas como Estados Unidos y en la cercanía de una campaña presidencial. En cualquier caso, todas las potencias parecen de acuerdo en que España no podrá terminar con la insurrección en los próximos meses y en que sólo

41 PRO/FO72/2006. Wolff a Salisbury, Madrid, 20 junio 1896, telegrama 66, secreto y confidencial. PRO/FO72/2004. Wolff a Salisbury, Madrid, 20 junio 1898, despacho 150, muy secreto y confidencial.

${ }^{42}$ PRO/FO72/2025. Wolff a Salisbury, Madrid, 25 junio 1896, despacho 69, secreto y confidencial.

43 Ibidem. Salisbury a Wolff, Londres, 2 julio 1896, telegrama 29.

44 PRO/FO72/2004. Wolff a Salisbury, Madrid, 3 julio 1896, despacho 157, alto secreto y confidencial.

Hispanit, LVII/2, núm. 196 (1997) 515-549 
un rápido acuerdo con los rebeldes podrá evitar la intervención de la república norteamericana ${ }^{45}$.

El 28 de julio, el duque de Tetuán comunicó a los Gobiernos de las potencias lo que después considerará el borrador del memorándum que preparaba; el texto permite finalmente precisar las dos cosas que deseaba el Gobierno de Cánovas: en primer lugar, que las potencias instasen al Gobierno norteamericano a que asumiera un compromiso rotundo, formal y público de no permitir que se produjera ninguna ayuda a los cubanos, en segundo lugar, que las potencias ofrecieran al embajador de España en Washington su apoyo y ayuda en las gestiones que realizase sobre este asunto cerca del Gobierno norteamericano. En las cartas que acompañan al texto del memorándum, el Gobiemo español se extendía en las consideraciones que, a su juicio, aconsejaban los pasos que proponía: la defensa del régimen monárquico en España y el peligro, no sólo para España y sino también para todos los intereses europeos en América, de una intervención norteamericana en Cuba ${ }^{46}$.

A esas alturas, el duque de Tetuán ya era consciente de que el entusiasmo desplegado por el embajador británico en Madrid -entusiasmo que posiblemente le había llevado a valorar de manera equivocada las palabras tan poco comprometedoras de Salisbury que le debía haber transmitido Wolff- no se correspondía con la reserva del Gobierno de Londres que le llegaba por otros conductos. En cualquier caso, el ministro de Estado español no estaba percibiendo correctamente la situación tal y como demuestra el mísmo día 28 en el despacho que envía al embajador de España en Londres acompañando el texto de su memorándum con las instrucciones para ser entregado en el Foreign Office:

«Te advierto con toda reserva y únicamente para tu gobierno... que Salisbury me ha hecho decir por conducto de Wolff en nota verbal o al menos papel escrito que trajo a su vuelta de Londres y del que me dió lectura, que si bien el Gobierno inglés, en razón de las circunstancias especiales que concernían actualmente en sus relaciones con el de los E. Unidos no nos podían ofrecer tomar iniciativa alguna, en cambio me aseguraba que apoyaría eficazmente nuestros intereses si de defenderlos o ocuparse en su favor se encargaba cualquier otra potencia de Europa. Esta satisfactoria declaración me ha sido repetidamente hecha por Wolff en diferentes conversaciones que con él he tenido y no es ciertamente de los que menos se ha agitado y movido con sus colegas en Madrid en sentido favorable a España.

No me explico, pues, la reserva que contigo se ha expresado ese Ministro de Neg. Extrang. en la conferencia de la que me das cuenta en uno de tus últimos des-

AS PRO/FO72/2025. Embajador británico en Viena a Salisbury, Viena 4 y 9 julio 1896, despachos 215 y 217 , secretos y confidenciales.

46 Archivo del Ministerio de Asuntos Exteriores (AMAE). Archivo histórico (H). Legajo 2416: Política, política exterior, EEUU 1896. Duque de Tetuân, ministro español de Asuntos Exteriores, a todos los embajadores españoles cerca de las grandes potencias, Madrid, 28 julio 1896 . Un estudio pormenorizado de la politica que está detrás de la preparación, envio y fracaso del memorándum en RoBles MuÑoz, Cristóbal: «Negociar la paz en Cuba (1896-1897)», en: Revista de Indias, 1993, vol. LJIl, núm. 198, págs. 493-527. 
pachos, ni de los términos en que me dices ha hablado con el Embajador de Austria que sé son también los mismos con que lo ha hecho con el de Francia. Posiblemente es que haya procedido así para no contraer compromisos anticipados con esos Gobiernos en tanto no conozca el Memorándum y tú no le hayas hablado oficialmente por mi encargo; ya iremos esclareciendo esta contradicción con el tiempo y tu consenson" ${ }^{47}$.

o Wolff desobedeció a Salisbury y en vez de repetir las palabras que el primer ministro había mandado poner por escrito pronunció ante Cánovas y Tetuán otras distintas, lo que en principio me resulta impensable, o el ministro español de Estado estaba cometiendo el error de traducir una simple expresión de sentimientos amistosos, y un educado ofrecimiento de estudiar una posible petición española de buenos oficios desde esos sentimientos, con la expresión de una promesa de apoyo eficaz a los intereses españoles si otra potencia europea tomaba la iniciativa.

En cualquier caso, el ministro español saldrá pronto de su error: tras la presentación de su memorandum, los representantes europeos en Madrid pasaron del entusiasmo a la reserva y de la reserva a la indiferencia; da la sensación de que, cuando se acercó el momento de poner en práctica el plan, todos los Gobiernos - no sólo el de Londres - frenaron a sus embajadores. El 27 de julio, la proclamación formal de la neutralidad norteamericana en la guerra de Cuba por parte del Gobierno Cleveland terminará de enfriar la anterior actividad a pesar de los esfuerzos del duque de Tetuán para ligar la acción que solicitaba con la posible mayor agresividad de la nueva Administración McKinley ${ }^{48}$. También tuvieron que influir en el enfriamiento de las potencias europeas, los datos que en aquel momento pudieran tener del enfrentamiento anglo-norteamericano por la cuestión de la disputa fronteriza entre la Guayana Británica y Venezuela. La dureza con la que el Gobierno Cleveland había obligado a Salisbury a aceptar una mediación no-querida en la cuestión no podía pasar desapercibida. El detonante de la nueva situación será el ministro plenipotenciario norteamericano en Madrid, Harris Taylor, que, enterado de lo que estaba preparando el gobierno español, se apresuró a señalar al duque de Tetuán, y a sus colegas en Madrid, que Estados Unidos consideraría la presentación del memorándum como un acto inamistoso. El 10 de agosto Taylor se entrevistó con Tetuán y al día siguiente Tetuán comunicó a Cánovas que, ante la reacción del ministro plenipotenciario norteamericano, enterado desgraciadamente del plan que se preparaba, y ante los consejos de Francia y de Inglaterra, que ya no apoyaban la idea, se había visto obligado a prometer a Taylor la suspensión de la presentación formal del memorándum a las potencias ${ }^{49}$. Aunque Tetuán, que responsabilizó a Wolff de la filtración de su

47 Ibidem. Duque de Tetuán a Marqués de Casa Valencia, Mađríd, 28 juljo 1898.

48 PRO/FO72/2026. Wolff a Salisbury, San Sebastián, 4 agosto 1896, despacho 179, muy secreto y confidencial.

49 AMAE/H/2416, Tetuán a Antonio Cánovas del Castillo, presidente del Consejo de Ministros, Madrid, 11 agosto 1898 .

Hisplania, LVII/2, núm. 196 (1997) 515-549 
1895-1898; INGLATERRA Y LA BÚSQUEDA DE UN COMPROMISO INTERNACIONAL 537

iniciativa, deje pasar todo el mes de septiembre y parte del de octubre sin dar por cerradas de manera definitiva las exploraciones previas, los embajadores en Madrid, que conocían la reacción de Taylor, aconsejaron la retirada del memorándum considerando que la proclamación de neutralidad que acababa de realizar el presidente Cleveland podía calmar los temores españoles ${ }^{50}$. Se abría un compás de espera que la diplomacia española parecía abordar con demasiado optimismo: mientras Cánovas, en su intervención el Congreso de los Diputados el 17 de agosto, afirmaba que España debía prepararse a sostener por sí sola la posesión de Cuba ${ }^{51}$, Tetuán, en su despacho al presidente del Consejo del 11 de agosto de 1896, era mucho mas optimista: «Las grandes potencias no podrán negar nunca que conocen nuestros propósitos y aspiraciones, y como todas probablemente aprobarán la conducta que hemos seguido, resultará implícitamente asociadas a la responsabilidad de nuestra resolución" ${ }^{52}$. El duque de Tetuán vuelve a equivocarse; su iniciativa, que, por supuesto, se ocultará a las Cortes y a la opinión pública, había fracasado; no había logrado la puesta en marcha de una acción colectiva de las potencias europeas para frenar a Estados Unidos y el hecho de que esas potencias conocieran las aspiraciones españolas no garantizaba ni su aprobación ni su futura asociación si se materializaban los negros presagios que suscitaba la prevista llegada, el 4 de marzo de 1897, de los republicanos a la Casa Blanca. El duque de Tetuán tendrá ocasión de comprobar lo infundado de sus esperanzas cuando quiera volver a concitar una acción colectiva de las potencias europeas tras la reiteración de la oferta de mediación que le hace, el 23 de septiembre, Stewart L. Woodford, el nuevo representante del Gobierno de los Estados Unidos.

\section{EL RECURSO A LAS POTENCIAS EN EL, INICIO DE LA CRISIS DE 1898}

Desde octubre de 1896, punto final de la iniciativa del duque de Tetuán, y septiembre de 1897, llegada a España del nuevo ministro plenipotenciario nombrado por la nueva Administración norteamericana, mientras la situación en Cuba se deterioraba, la diplomacia española permaneció a la espera de acontecimientos. El embajador británico en Madrid aprovechó la espera para proporcionar a su Gobierno una mejor y más detallada información de lo que estaba ocurriendo en España. Aunque a mediados de octubre transmita palabras del duque de Tetuán negando que existiera un entendimiento hispano-francés y quitando importancia a las consecuencias de la insurrección de Filipinas, muy pronto, a partir de noviembre, la actividad del embajador se centrará en una serie de largos informes sobre la situación crítica en la que se

so PRO/FO72/2026, Wolff a Salisbury, San Sebastián, 14 agosto 1896, despacho 185, muy secreto y confidencial.

st Congreso de los Diputados. Sesión de 17 agosto 1896. Diario de Sesiones, pág. 2395.

52 AMAE/H/2416. Tetuán a Cánovas, Madrid, 11 agosto 1896, copia de carta reservada. 
encontraría el Gobierno español en los meses que se avecinaban. El embajador consideraba que los recursos españoles se estaban terminando y que la posible intervención norteamericana podría tener graves consecuencias, cambio dinástico incluido; el riesgo que el embajador advertía en ese momento no se refería tanto a la posibilidad de éxito de un levantamiento carlista, como a la sustitución de la Regente. Posiblemente porque sabía que la Reina Victoria y el premier Lord Salisbury sentían un evidente cariño por doña Cristina, el embajador, que no había renunciado a empujar a su Gobierno hacia una política de apoyo a España, se detendrá en los rumores sobre la «aversión personal» de Cánovas hacia la Regente y avisará de la posibilidad de que, si la situación se agravaba, la Regencia pudiera pasar a manos de la infanta Isabel. Sus conversaciones con Moret permiten a Wolff incluir en sus despachos unas opiniones que venían a ratificar sus impresiones: el tipo de guerra que hacían los rebeldes no se podía ganar, España se estaba arruinando y no existían hospitales para tantos soldados enfermos y heridos: era imprescindible negociar ${ }^{53}$. A principios de febrero de 1897 la preocupación británica se centrará en la posibilidad de que el Gobierno español esté negociando con Francia la venta de alguna de las islas Canarias a cambio de apoyo financiero ${ }^{54}$. El desmentido del duque de Tetuán volvió a concentrar a Wolff en la redacción de informes sobre la situación española: incremento de los movimientos carlistas, catalanismo y mejora de la relaciones hispano-alemanas son los temas que predominan en sus largos despachos ${ }^{55}$.

La atención del Gobierno español y de las Embajadas y Legaciones de las grandes potencias en Madrid se tensará cuando se acerque la presentación de cartas credenciales del nuevo ministro plenipotenciario norteamericano. Se supone que Woodford llegará provisto de instrucciones estrictas y precisas sobre la cuestión cubana. El embajador británico, que trasmite su impresión de un país sumido en la indiferencia, el fatalismo y la inercia, considera que los dos partidos turnantes están decididos a conceder la autonomía a Cuba y a descargar la responsabilidad de esta impopular medida en la Regente; sus entrevistas con Taylor le permiten establecer un cuadro muy vívido de la percepción norteamericana de lo que estaba pasando en Cuba, de lo que podría esperarse del Gobierno Cánovas y de las posibilidades de un Gobierno Sagasta ${ }^{56}$.

Stewart L. Woodford llegó a San Sebastián el 2 de septiembre; para evitar pérdidas de tiempo que pudieran ser mal interpretadas, entregará sus cartas credenciales en el lugar de veraneo de la Corte. Nada mas llegar, el nuevo

5.3 PRO/FO72/2005. Wolff a Salisbury, San Sebastián, 16 octubre y Madrid, 9 y 24 noviembre y 3 diciembre 1896 , despachos $232,259,275$ y 281 .

S4 PRO/FO72/2033. Wolff a Salisbury, Madrid, 8 y 16 febrero 1897, despachos 40 y 45 .

ss lbidem. Wolff a Salishury, Madrid, $15,17,18$ y 19 marzo y 14 y 17 abril 1897 , despachos $76,77,81,84,108$ y 109 .

56 PRO/FO72/2056, Wolff a Salisbury, San Sebastián, 11 y 13 julio 1897, despachos 180 y 181 , muy confidenciales. PRO/FO72/2035, Wolff a Salisbury, San Sebastián, 30 julio 1897, despacho 191, confidencial.

Hispania, LVI1/2, núm. 196 (1997) 515-549 
ministro plenipotenciario norteamericano sostuvo varias entrevistas con el embajador británico. A través de los informes de Wolff podemos documentar la posición y los argumentos del representante del presidente McKinley, las razones que justificaban la necesidad norteamericana de terminar lo antes posible con la guerra de Cuba ${ }^{57}$. El 18 de septiembre, después de presentar a la Reina Regente sus cartas credenciales, Woodford se entrevistó con el duque de Tetuán y le entregó una Nota con la exigencia norteamericana de que España pusiera fin a la guerra en Cuba utilizando la mediación de los Estados Unidos. El ministro español tuvo que aplazar la respuesta; Cánovas había sido asesinado el 8 de agosto y el duque de Tetuán dejaba su puesto pocos días después de la entrevista con el representante norteamericano. El cambio de gobierno no pareció modificar los límites de la diplomacia española; el Gobierno liberal de Sagasta, con Moret en el Ministerio de Ultramar y con Pío Gullón en el de Estado, rechazó el 20 de octubre la mediación norteamericana, considerando que acceder a lo que pedía la Nota de Woodford suponía la suspensión de la soberanía española en Cuba, y recurrió a la acción diplomática cerca de las potencias europeas para obligar a Estados Unidos a desentenderse del asunto; comenzaba una importante gestión diplomática que implicará a todas las grandes potencias y al Vaticano y que no terninará hasta el estallido de la guerra hispano-norteamericana.

En realidad, como ponía de manifiesto el embajador Wolff en sus despachos, el nuevo Gobierno Sagasta nacía muy limitado como consecuencia de los enfrentamientos en el seno del Partido Liberal. La cartera de Estado había quedado en manos de Pío Gullón, antiguo periodista, en una ocasión subsecretario y anterior Gobernador del Banco de España; aunque se le suponía cercano a Moret no era evidentemente Moret y en el nuevo Gobierno no figuraban ni Gamazo ni su cuñado Maura. El embajador británico consideraba que el plan original de Sagasta había sido colocar a Gamazo en Ultramar y a Moret en Estado, y que esta combinación hubiese dado mas fuerza al Gobierno a la hora de diseñar soluciones para el problema cubano. Wolff consideraba que la posición proteccionista de Gamazo le había apartado de un Gobierno que, sin él, quedaba debilitado ${ }^{58}$. En cualquier caso, el nuevo Gobierno Sagasta intentará, desde el primer momento, mostrar a las potencias europeas su resolución. En la primera entrevista que Wolff realizó con Moret siendo este ya ministro de Ultramar, su confidente de tantas ocasiones le expresa con toda claridad las expectativas españolas: el nuevo Gobierno ha retirado al general Weyler y está dispuesto a introducir reformas en Cuba que garanticen el desarrollo de instituciones libres y populares que restauren la tranquilidad y el orden; pero cualquier intento de Estados Unidos de intervenir con las intenciones que se derivaban de los términos de la Nota de Wood-

57 PRO/FO72/2035, Wolff a Salisbury, San Sebastián, 2 septiembre 1897, despacho 232. PRO/FO72/2056, Wolff a Salisbury, San Sebastián, 9 y 13 septiembre 1897, despachos 241, 244 y 245 , secretos y confidenciales.

58 PRO/FO72/2035. Wolff a Salisbury, Madrid, 5 octubre 1897, despacho 259, confidencial.

Hispania, LVII/2. nủm. 196 (1997) $515-549$ 
ford serían "la última ofensa»; España apelaría a Europa, "explicando los generosos propósitos del Gobierno español y si no tuviera éxito no dudaría en declarar la guerra", una guerra en la que España "recurriría al corso» ${ }^{59}$.

En cualquier caso, ante la Nota de Woodford, el Gobierno Sagasta puso en marcha una iniciativa diplomática en estricta continuidad con las iniciativas del anterior Gobierno conservador. La Regente se dirigió al emperador de Austria-Hungría; este, por su parte, aprovechó las maniobras militares que el ejército austro-húngaro estaba realizando con el alemán para informar del asunto al Káiser Guillermo. De manera paralela, el Gobierno se dirigió al embajador de Francia en Madrid para ponerle al corriente de sus deseos; el Gobierno francés se puso en comunicación con el Gobierno ruso. En un primer momento sólo el Káiser pareció interesado en la intervención; sin embargo, su ministro de Exteriores, Bernhard von Bülow, será mas precavido, recordará los intereses alemanes en Estados Unidos y colocará la política alemana en un segundo plano, cediendo la iniciativa y esperando la definición de posturas de las demás potencias ${ }^{60}$. Aunque tampoco el ministro austriaco de Exteriores Goluchowsky quiera asumir ningún compromiso previo, la presión del emperador Francisco José logrará finalmente que Austria-Hungría ponga en marcha la gestión a principios de diciembre. Mientras tanto, España presionará en dos direcciones paralelas: el Gobierno tratará de comprometer a cada bloque - Triple Alianza y Alianza franco-rusa- dando la impresión de que el otro estaba dispuesto a actuar, y la Regente escribirá a varios monarcas pidiéndo que apoyasen la gestión de sus Gobiernos. A pesar de los esfuerzos del embajador Wolff para convencer a Salisbury de que Rusia y Francia se "habían puesto en marcha», el Gobierno británico no respondió a ninguna de las sugerencias que se formulan. A lo largo de estos meses, todas las potencias se limitaron a darse por enteradas de los, por otra parte, inconcretos deseos españoles de contar con su colaboración. En general, cada una se reservó a la espera de conocer con claridad las intenciones de las demás mientras señalaban algo que se convertirá en un lugar común a lo largo de todas estas semanas: la importancia de la posición que adoptase Inglaterra. A pesar de los nuevos informes de Wolff detallando los dilemas a los que se enfrentaba la política de Sagasta, las malas formas de los conservadores romeristas hacia la Regente y sus temores sobre un desenlace desastroso de la crisis española 61, el marqués de Salisbury se limitará a repetir sus anteriores expresiones y consideraciones: puede asegurar al señor Moret, le dice el 19 de octubre, «nuestro amistoso interés en todo lo que concierne al bienestar de España y de sus colonias" y, desde el recuerdo de la crisis de la frontera de Venezuela,

\footnotetext{
59 PRO/FO72/2056. Wolff a Salisbury, Madrid, 11 octubre 1897, despacho 264, secreto y confidencial.

so ÁlVAREZ GưtírReZ, Luis: «La diplomacia alemana ante el conflicto hispano-norteamericano de 1897-1898: primeras tomas de posición». En: Hispania, LIV/1, núm. 186 (1994), págs. 201-256.

61 PRO/FO72/2035, Wolff a Salisbury, Madrid, 17 octubre 1897, despacho 272, verdaderamente secreto y confidencial. PRO/FO72/2056, Wolff a Salisbury, Madrid, 18 octubre 1897, despachos 273 y 275 , secretos y confidenciales:

Hispania, LVII/2, лйm. 196 (1997) 515-549
} 
1895-1898: INGLATERRA Y LA BÚSQUEDA DE UN COMPROMISO [NTERNACIONAL 54]

añade, «aunque difícilmente pueda conocer lo que significa en este caso apoyo moral, tengo claro que apoyo inglés significa en muchos casos hostilidad americana» ${ }^{62}$.

\section{LA CRISIS DEL MAINE Y LA INTERVENCIÓN DE LAS POTENCIAS}

La iniciativa española se relanzó angustiada el 15 de febrero de $1898^{63}$; la destrucción del Maine en el puerto de La Habana, llevó al Gobierno Sagasta a realizar una solicitud formal de intervención de las grandes potencias que dirigió en primer lugar a Berlín y París. De nuevo las gestiones tuvieron como protagonista a la Regente y al Gobierno, y de nuevo Alemania y Francia se mostraron dispuestas a hacer una gestión diplomática en Washington si otra potencia - ahora se piensa en Austria-Hungría - tomaba la iniciativa.

A mediados de marzo, mientras espera que las grandes potencias concreten una acción colectiva en Washington que desactive la crisis del Maine, el ministro Gullón es consciente de que el problema del Pacífico condiciona la política británica y cuenta con la posibilidad de un acercamiento anglo-norteamericano:

«Si la tirantez de relaciones entre Inglaterra y Rusia llegara a formalizarse, los términos del problema se aclararían, en mi concepto, muy pronto y Vd. podría penetrar en breve lo que la reserva de Lord Salisbury oculta al presente con tanto empeño. Con Rusia coinciden, según me dicen, en el extremo Oriente no sólo Alemania sino la vecina Francia. Si los intereses de la Gran Bretaña definitivamente separasen a ésta del Czar, parece posible que el Gabinete de SaintJames no sólo buscará en el extremo Oriente el apoyo de Japón, sino que se acercará también a los Estados Unidos» ${ }^{64}$.

La intervención de las potencias tardará en hacerse realidad. Se necesitaba la participación de Inglaterra y el Gobierno británico se mostraba especialmente cauteloso. Es posible que esa cautela especial tenga algo que ver con el hecho de que en esas semanas la diplomacia británica no estuviera dirigida por el marqués de Salisbury, sino por Arthur James Balfour, miembro del Gabinete como primer Lord del Tesoro y sobrino y heredero político del premier, que se hacía cargo del Foreign Office cuando Salisbury viajaba fuera del país. Pués bien, si el viejo Salisbury - partidario de que Inglaterra mantuviese la política de free hand y no buscase alianzas internacionales para defender sus intereses- había valorado la amistad norteamericana en el Pacífico por encima de la amistad española en el Mediterráneo Occidental y no había auto-

62 PRO/FO72/2036. Salisbury a Wolff, Londres, 19 octubre 1897, telegrama 34, borrador.

63 Companys Monclus, Julián: De la explosión del Maine a la ruptura de relaciones diplomáticas entre Estados Unidos y España (I898), Quaderns del Departament de Geografja i Història de l'Estudi General de Lleida, 1989.

64 AHN/Estado/8664. Gullón a Rascón, Madrid, 11 marzo 1898.

Hispania, LVII/2, nu்m. 196 (1997) 515-549 
rizado ni un sólo paso que sacase a Inglaterra de la más estricta neutralidad en el conflicto cubano, el joven Balfour -convencido, como el ministro de Colonias Joseph Chamberlain, de que la política exterior de Salisbury no era la más adecuada para la nueva situación internacional y de que era necesario seguir intentando una alianza con Estados Unidos- tendrá una posición en el conflicto hispano-norteamericano que si bien no se separará de las instrucciones previas de Salisbury, se expresará con una contundencia todavía mayor. Para empezar, en sus instrucciones a las Embajadas británicas en Madrid y Washington, Balfour había dejado muy clara su posición: «... ni... (en Londres) ni en Washington, tiene el Gobierno británico el propósito de dar ningún paso que pueda no ser aceptable para el Gobierno de los Estados Unidos" " ${ }^{5}$. Sobre esta base, Balfour dió una cierta autonomía a sir Julian Pauncefote, embajador británico en Washington, amigo personal del secretario de Estado norteamericano William Day, para que sondease al Gobierno del presidente McKinley; como en un primer momento, el presidente norteamericano señaló al embajador británico que la intervención de las grandes potencias europeas no sería aceptada por considerarla prematura, Balfour retrasará la intervención en espera del visto bueno norteamericano ${ }^{66}$.

Mientras esperaba que pudiesen concretarse los buenos oficios de las potencias, Gullón seguía muy interesado en escudriñar la posición de Inglaterra:

«...comprendo que la ausencia de Salisbury -telegrafía el ministro a Rascón el 16 de marzo- aumentará dificultades de V.E. para ciertas investigaciones reservadas, y quisiera sin embargo que a todo trance procurara V.E. averiguar si la Gran Bretaña tiene en realidad algún compromiso contraído con los Estados Unidos para eventualidades del porvenir o si su reserva y su mutismo nacen sólo del deseo de encontrarse libre sin haber adquirido todavía obligaciones tácitas o expresas con aquella República. Cuanto usted pueda decirnos en breve plazo ha de sernos de mucha utilidad, pero quizá convenga no buscar tales informes en Drummond Wolff, 67 .

Pero los días pasaban y la crisis del Marne se complicaba cada vez más. La paralización que Balfour estaba imponiento a la acción conjunta de las potencias llevará a la Regente a dirigirse, el 17 de marzo, a la Reina Victoria en unos términos verdaderamente patéticos:

«... Con toda mi confianza en usted le escribo para darle a conocer mi dificil situación, convencida de que me dará su poderoso auxilio y buen consejo. Hasta aquí España ha luchado sola contra las dificultades, vencíendolas todas, una

65 PRO/FO72/2067. Arthur Janes Balfour, primer lord del Tesoro, a George Barclay, primer secretario de la Embajada británica en Madrid, Londres, 26 y 31 marzo 1898, telegramas. PRO/FO72/2061, Balfour a sir Julian Pauncefote, embajador británico en Washington, Londres, 6 abril 1898, telegrama.

6G Neale, R.G.: Ob. cit. págs. 13-14.

67 AMAE/H/2417. Gullón a Rascón, ,Madrid, 16 marzo 1898, telegrama.

Hispamia, LVH/2, núm. 196 (1997) 515-549 
1895-1898: INGLATERRA Y LA BÚSQUEDA DE UN COMPROMISO INTERNACIONAL 543

después de otra. Ahora es preciso incluir la guerra con Cuba: todo lo ha hecho nuestro pobre país sin ayuda ajena. Ha sacrificado a sus hijos por la Patria, ha dado su dinero para la guerra y aún hoy está dispuesta a cualquier sacrificio.

Nosotros hubéramos terminado esta guerra en Cuba hace tiempo si los Estados Unidos hubieran permanecido neutrales, pero continuamente han enviado dinero, municiones y armas a los rebeldes; y ahora que la revolución está casi vencida los americanos quieren provocarnos a una guerra que yo deseo cvitar como sea. Pero todo tiene un límite y yo no puedo permitir que mi país quede humillado por los Estados Unidos.

Hasta ahora no he querido molestar a nadie con mis asuntos, y lo hago ahora sólo para mantener la paz. He acudido al Emperador de Austria, que me prometió acercarse a las otras potencias para alcanzar una acción común que tuviese el objetivo del manteniemiento de la paz; pero he querido dirigirme a usted directamente para al mismo tiempo suplicarle que no me niegue su poderosa protección. Conozco su gran bondad, manifestada a favor de mi hijo huérfano de padre. Por su bien le suplico que me ayude. Sería desolador para mí si Inglaterra no cooperara con las otras grandes potencias en este asunto" ${ }^{68}$.

Es evidente que la participación de Inglatarra era imprescindible. Lo era si se trataba sólo -como finalmente se tratará- de una acción colectiva de buenos oficios de las seis grandes potencias en Washington, lo era todavía más si se trataba - como en realidad deseaba la diplomacia española- de que siguiese funcionando en la zona del Caribe un esquema diplomático en el que Francia e Inglaterra se comprometiesen a fondo con la defensa de su statu quo colonial. Por supuesto, la sequedad de Balfour impidió a la diplomacia española expresar con claridad sus deseos ante el Gobierno de Londres, pero en París las cosas eran distintas, allí, el embajador León y Castillo tuvo la oportunidad de ser claro y de hacerse ilusiones poco fundamentadas:

«Juzga grave (Hanotaux) situación lamentándose lentitud negociaciones relativas iniciativas tomadas Emperador de Austria, examinando fases diversas cuestiones y encontrándole decidido en nuestro favor hasta el punto de preguntarme qué haría yo por España en su lugar, díjele que a más cooperar activamente para obtener concierto europeo, como la crisis ha llegado a periodo agudo y exige acción rápida, yo cré́a que Francia, invocando la tradición de la política internacional de ambas naciones respecto a Cuba desde comienzo de siglo, se dirigiera Inglaterra para proponerle acción común en pro mantener paz" ${ }^{6}$.

El 26 de marzo, sin que la iniciativa puesta en marcha se concrete como consecuencia de la decisión de Balfour de esperar a que el Gobierno de Washington la acepte previamente, el Gobierno Sagasta supo que el presidente McKinley iba a enviar al Congreso el informe que, sobre la explosión del Maine, había elaborado la comisión de investigación norteamericana. Cons-

1.8 The Letters of Queen Victoria..., 1ll, carta de la Reina María Cristina a la Reina Victoria, Madrid, 17 marzo 1898, págs. 236-237.

69 AMAE/H/2417. Fernando León y Castillo, embajador español en Francia, a Gullón, París. 25 marzo 1898 , telegrana.

Hixpaniz. LVII/2, núเr. 196 (1997) \$15-549 
ciente de los peligros que derivarían de ese hecho, se apresuró a buscar los buenos oficios de Inglaterra para que el presidente mantuviera «dentro de la jurisdicción del Ejecutivo todo lo referente a las diferencias con España con vistas a llegar a un acuerdo honorable" ${ }^{70}$. La respuesta de Balfour fue negativa y especialmente rotunda:

«El Gobierno de Su Majestad vería con pesar cualquier incidente innecesariamente dispuesto para envenenar las relaciones entre España y los Estados Unidos. Pero no puede pensar que se conseguiría un final provechoso ofreciendo a Estados Unidos un consejo no solicitado sobre un asunto tan obviamente dentro de sus competencias como el momento y la forma de comunicar al Congreso un informe de sus propios funcionarios" ${ }^{71}$.

En la última decena de marzo, en espera de que el Gobierno británico considerase adecuado el momento, las grandes potencias van decidiendo su intervención diplomática en Washington conscientes de las dificultades que tenía España para aceptar un compromiso que pudiera satisfacer a los norteamericanos. Pensando en ello, von Bülow había sugerido al Gobierno español el recurso a una mediación papal, paralela y autónoma, con objeto de completar la acción de las grandes potencias en Washington con un consejo papal que ayudase al Gobierno español a justificar las concesiones a los rebeldes cubanos ante una opinión pública que se consideraba peligrosamente hostil a ellas.

El 29 de marzo la crisis hispano-norteamericana volverá a acelerarse; en esa fecha, el general Woodford entregó a Sagasta, en presencia de Gullón y Moret, ministros de Estado y Ultramar respectivamente, el famoso apunte que resume las exigencias de su Gobierno: inmediata pacificación de la isla de Cuba, negociación de la paz a través del presidente McKinley y revocación de la orden de los reconcentrados. El Gobierno español, que aceptará la petición sobre los reconcentrados, siguió sin mostrarse dispuesto a colocar el problema de Cuba en las manos de los Estados Unidos y no aceptó la concesión de un alto el fuego que no habran pedido los insurrectos. Consciente de que, con sus negativas, empeoraba la situación, el Gobiemo español volvió a dirigirse a las potencias en busca de apoyo.

El hecho de que sea Balfour, no Salisbury, quién se encuentre en estas semanas al frente del Foreign Office, podría llevarnos a considerar que el retraso impuesto por la Administración norteamericana, a través de Inglaterra, a la acción colectiva de las potencias no se hubiera producido si el viejo premier hubiese estado en Londres. Sin embargo, conviene no precipitarse y valorar la carta que, desde Francia, donde se encontraba reponiéndose de su mala salud, envió el 1 de abril Salisbury a la Reina Victoria en respuesta a su remisión de la copia de la carta de 17 de marzo de la Reina Regente de España:

«... La cuestión española es tmuy grave y Lord Salisbury no desearía aconsejar a Su Majestad que realizase algún empeño para ayudar a la Reina de España sin

70 Neale, R.G.: Ob. cit., pág. 13.

7 Jbidem, pág. 14.

Hispania, LVII/2, núm. 196 (1997) 515-549 
1895-1898: INGLATERRA Y LA BÚSQUEDA DE UN COMPROMISO INTERNACIONAL 545

consultar con sus colegas (de Gabinete), porque toda comunicación de Inglaterra a los Estados Unidos en forma de censura podría provocar susceptibilidades y producir una situación de algún peligro sin ningún correspondiente beneficio. Al mismo tiempo, Lord Salisbury estima que Su Majestad no debería rehusarse a cooperar con las otras potencias en cualquier iniciativa que tomasen; pero duda del éxito de tal acción, que mas bien ayudaría al partido de la guerra en los Estados Unidos. La posición de la Reina Regente es lamentable y digna de piedad. Es imposible no sentir por ella la más profunda simpatía» ${ }^{72}$.

El convencimiento de Salisbury de que cualquier censura a los Estados Unidos podía producir susceptibilidades peligrosas para Inglaterra sin ningún beneficio para España, no es distinto del que sustenta las decisiones de Balfour.

En cualquier caso, a comienzos de abril, coincidirán en Washington las dos acciones diplomáticas. Por un lado, monseñor Ireland intentará parar la guerra que se avecina negociando la suspensión de hostilidades en Cuba ${ }^{73}$. Por otro lado, los representantes de las seis grandes potencias europeas seguirán las indicaciones de sus Gobiernos y prepararán una Nota para ser entregada al presidente McKinley. No debernos olvidar que el Vaticano no tenía representación diplomática ante el Gobierno norteamericano y que, por lo tanto, no era posible la integración de Ireland en el contexto de las potencias; además, cada una de las acciones diplomáticas va a tener un sentido distinto: las potencias intentaban ejercer una cierta presión moral sobre los partidarios de la guerra en Washington para fortalecer la posición del presidente, considerando que éste era contrario a esa solución, y el Vaticano buscaba facilitar al Gobierno español la puesta en marcha de medidas dolorosas y que se suponían muy anti-populares.

El día 3 de abril, el Gobierno español, pensando que McKinley aceptaba la mediación papal, se comprometió a aceptar la propuesta de cese de hostilidades de León XIII, y pidió a Washington que retirase sus barcos de las Antillas. En Washington, sir Julian Pauncefote, embajador británico y decano del cuerpo diplomático en la capital norteamericana, terminó de redactar la Nota de común acuerdo con el secretario de Estado norteamericano, en la confianza mutua de que la iniciativa europea podría calmar la agitación popular en Estados Unidos. El 6 de abril se reunieron los embajadores de las seis grandes potencias europeas en la Embajada británica y aprobaron la Nota que Pauncefote y Day habían redactado. Los reunidos esperaban que su Nota, que apelaba a los "sentimientos de humanidad y moderación" del presidente y del pueblo norteamericano, expresaba la esperanza de que el «humanitarismo y la

72 The Letters of Queen Victoria..., IIl, carta de lord Salisbury a la Reina Victoria, Beaulieu, 1 abril 1898, págs. 239.

${ }^{73}$ OFFNER, John: «President McKinley's final attempt to avoid war with Spain», en: Ohio History, vol. 94, summer-autum 1985, págs. 125-138; «Washington Mission: Archbishop Ireland on the eve of the Spanish-American Wan, en: The Catholic Historical Review, vol, LXXIIl, october 1987, págs. 562-575. RoBles MuÑoz, Cristóbal: «1898: la batalla por la paz. La mediación de León XIII entre España y los Estados Unidos», en: Revista de Indias, 1986, vol. XLVI, núm. 177, págs. 247-289.

Hisponia, LV]1/2, mim, 196 (1997) $515-549$ 
puramente desinteresada" mediación de ambos, ayudaría a restablecer y mantener el orden en Cuba. La Nota fue entregada por los seis embajadores en la Casa Blanca a medio día del 7 de abril; McKinley les recibió amistosamente en la Biblioteca y les dio las gracias por sus esfuerzos en favor de la paz.

Aunque ni la intervención de monseñor Ireland ni la de las potencias consiga apartar a los Estados Unidos de la línea política que venía desarrollando en la cuestión cubana, el Gobierno español mantendrá su compromiso de suspender las hostilidades en Cuba, pero, para presentar esa concesión unilateral de la manera menos peligrosa posible para al Régimen, se organizó una apariencia de acción colectiva de todas las grandes potencias en Madrid. En la noche del 8 de abril, el embajador austriaco en la capital de España, informó a los otros representantes de las grandes potencias, que estaban reunidos en la Embajada alemana, de que la Regente le había expresado, de manera muy confidencial, su deseo de que las potencias, individual o colectivamente, aconsejasen al Gobierno español que aceptase la petición del Papa y proclamase la inmediata suspensión de hostilidades en Cuba. La Regente deseaba que la intervención formal de los embajadores en el Ministerio de Estado se realizase al día siguiente, en la mañana del 9 de abril; los embajadores, que no tuvieron tiempo para consultar con sus ministros, estuvieron de acuerdo en que, aunque la Nota fuera colectiva, el consejo debía ser británico. El día 9 de abril, a las 10 de la mañana, los representantes de las grandes potencias acudieron al Ministerio de Estado, se entrevistaron con Pío Gullón y le entregaron, "como corolario" de la acción que las potencias habían realizado el 7 de abril en Washington, una Nota en la que pedían al Gobierno español, la suspensión de hostilidades en Cuba ${ }^{74}$.

\section{EL PROBLEMA DE LA SEGUNDA NOTA}

Como hemos visto, la Nota del 7 de abril no fue en ningún caso un acto hostil hacia los Estados Unidos; no fue ni siquiera un acto de presión diplomática y la Administración norteamericana así lo interpretó. Otra cosa distinta hubiese sido la presentación de la segunda Nota que preparó pocos días después el embajador Pauncefote. En efecto, si antes del día 11 de abril, el embajador británico, como el resto de sus colegas, estaba convencido de que la suspensión de hostilidades en Cuba daba a España una gran fuerza moral y facilitaba la continuación de la intervención de las potencias ${ }^{75}$, cuando McKinley ponga la cuestión de Cuba en manos del Congreso, no dudará en aceptar de inmediato la propuesta del embajador austro-húngaro y empezará

74 PRO/FO72/2068. Barclay al Foreign Office, Madrid, 9 abril 1898, telegrama, muy reservado. En las semanas en las que se prepara la intervención de las potencias del mes de abril de 1898 , Wolff no está en Madrid. En esta como en otras ausencias del embajador, ja Embajada británica en Madrid quedaba en manos de George Barclay, su primer secretario.

$75 \mathrm{AMAE} / \mathrm{H} / 2417$. Polo de Bernabé, ministro plenipotenciario de España en Estados Unidos a Gullón, Washington, 10 abril 1898, telegrama.

Hisparia. LVII/2, núın. 196 (1997) 515-549 
a preparar una segunda Nota; enfurecido por las expresiones del mensaje que el presidente McKinley envió al Congreso de los Estados Unidos el 11 de abril, el embajador británico cometió el que posiblemente sea el único error de una brillante y larga carrera diplomática ${ }^{76}$; sin consultar con Balfour, Pauncefote convocó el día 14 de abril a los embajadores de las otras cinco potencias y sometió a la consideración de sus respectivos Gobiernos el texto de una nueva Nota que debería ser entregada, si contaba con las aprobaciones correspondientes, a los embajadores de Estados Unidos en las capitales de las seis potencias europeas. En principio se prodría considerar que la iniciativa de Pauncefote se debía a su condición de decano del cuerpo diplomático en Washington, pero los embajadores francés y alemán en aquella capital, que asistieron a todas las reuniones convocadas por Pauncefote en su Embajada, nos han dejado datos que obligan a profundizar algo más en las razones del embajador británico. Jules Cambon y Holleben telegrafiaron a sus respectivos gobiernos que Pauncefote les citó y que adoptó en la reunión un papel dirigente y enérgico. Cambon, en particular, trasmitió a París que Pauncefote llegó a exclamar que las potencias no podían permitir que los Estados Unidos cometieran "un acto de bandidaje" sin expresar su protesta en nombre de "la conciencia pública de Europan "7. Pauncefote, que cuando se produjo la explosión del Maine informó a su Gobierno que no cré́a que la explosión hubiera sido obra de los españoles, quedó profundamente afectado por lo que significaba el mensaje de 11 de abril de McKinley a Congreso; entiendió que la Administración norteamericana avandonaba su anterior oposición a la guerra y el discurso de McKinley ofendió su sentido de la moralidad. Sobre esta base, el embajador británico propuso a sus colegas dejar claro ante los norteamericanos que la intervención armada que preparaban no contaba, a pesar de lo que había dicho el presidente McKinley en su mensaje al Congreso, con «el apoyo y la aprobación del mundo civilizadon; por el contrario, Pauncefote consideró que la Administración norteamericana debía valorar las concesiones que acababa de realizar España y que las potencias debian declarar formalmente "su incapacidad para apoyar una intervención armada cuya justicia no admiten" ${ }^{78}$. Polo de Bernabé, ministro encargado de los asuntos españoles en Washington, que conoció la reunión del día 14 de abril en la Embajada británica, debió pensar que por fín se cumplían los deseos españoles y telegrafió al Ministerio de Estado: «no veo imposibilidad de conseguir manifestación naval si Gobierno de S.M. (española) estimase oportuno gestionarla» ${ }^{79}$.

7h Mowart, R. B.: The Life of Lord Pauncefote, First Ambassador of the United States. Londres, Constable \& Co. Lid., 1929.

77 Documents Diplomatiques Français, 1871-1914, 10. Série (1871-1900), vol, XIV (4 enero 30 diciembre 1898), París, IN, 1957. Jules Cambon, embajador francés en Esiados Unidos a Gabriel Hanotaux, ministro de Asuntos Exteriores francés, Washington 14 abril 1898, telegrama.

$7 \%$ GRENVILLE, J. A. S.: Ob. cit., págs. 211-212.

$79 \mathrm{AMAE} / \mathrm{H} / 2417$. Polo de Bermabé a Gullón, Washington, 15 abril 1898 , telegrama muy reservado.

Hispania. LVII/2. num. 196 (1997) $515-549$ 
Balfour, reforzado por la opinión de Chamberlain, desautorizará la iniciativa del embajador británico. El 15 de abril, cuando el telegrama de Pauncefote, con el texto de la Nota que había propuesto a sus colegas, llegó al Foreign Office, Balfour no estaba en Londres; consciente de la importancia del asunto, el subsecretario le hizo llegar el texto con la mayor rapidez. Pues bien, sabemos que en menos de veinte minutos y sin consultar con nadie escribió la primera respuesta:

\begin{abstract}
«Estamos dispuestos a sumarnos a cualquier petición (representation) acordada por las otras potencias en favor de la paz. Estamos también dispuestos a hacer ver que no hemos formado un juicio adverso a España, como parece aceptado por el Congreso (de los Estados Unidos), y a manifestar la esperanza de que la concesión de un armisticio por parte de España puede ofrecer la oportunidad de un pacífico arrego. Pero parece dudosísismo que debamos comprometernos con un juicio adverso hacia los Estados Unidos y que los intereses de la paz ganen nada con ello. Puede usted hacerme, si lo considera conveniente, cualquier observación que su conocimiento local pueda porporcionarme respecto a esta opinión» 80 .
\end{abstract}

Enviado un telegrama a la Embajada de Washington con este texto, Balfour siguió dándole vueltas al problema y buscó al día siguiente el consejo de Chamberlain, al que remitió la propuesta austriaca de seguir presionando en Washington, el borrador de la Nota de Pauncefote y su respuesta del día anterior. Balfour señala a Chamberlain que, después de pensarlo con más cuidado, considera que debería haber enviado a Pauncefote un telegrama más rotundo para evitar la participación de Inglaterra en cualquier otra acción colectiva de las potencias: "Confieso mi perplejidad. Los representantes de las potencias en Washington y el embajador británico parecen desear que demos a los Estados Unidos una lección de moralidad internacional" ${ }^{81}$. Chamberlain se mostró de acuerdo con Balfour en que la Nota sólo conseguiría el resentimiento de los Estados Unidos hacia las potencias europeas en general y hacia Inglaterra en particular y consideró que su colega deberfa haber enviado al embajador Pauncefote instrucciones más rotundas, sin ninguna declaración en favor de España. El 17 de abril Balfour telegrafió de nuevo a Pauncefote ordenándole que detuviera cualquier iniciativa mientras Chamberlain precisaba las razones de su rotundidad:

«Me da miedo el daño que nuestra interferencia puede producir. La posición americana puede ser buena o mala, pero es muy clara; y pedirles que la cambien en nombre del Concierto de Europa (absit omen!) lo considerarán probablemente como una ofensa. Hasta ahora la opinión pública de los Estados (Unidos) ha reconocido agradecidamente que nosostros hemos procedido con mayor simpatía que las otras grandes potencias... Como éstas nunca nos ayudan ni agra-

80 PABÓN, Jesús: «El 98, acontecimiento internacional», en: Días de ayer. Historias e historiadores contemporáneos. Barcelona, Alpha, 1963, págs. 189-190.

81 lbidem, pág. 189.

Hispania, LVI/2, nủm. 196 (1997) 515-549 
1895-1898: INGLATERRA Y LA BÚSQUEDA DE UN COMPROMISO INTERNACIONAL 549

decen cualquier asistencia que les prestemos, mientras menos cosas hagamos con ellas será mejor. Pero lo hecho, hecho está. Y mi esperanza es la de equivocarme en cuanto al resultadon 82 .

El miedo de Chamberlain era infundado; en primer lugar, Pauncefote sólo necesitó la primera respuesta de Balfour para comprender que había ido mucho más lejos de lo que deseaba su Gobierno; en segundo lugar, sólo el Gobierno de Austria-Hungría estuvo dispuesto a entregar formalmente el texto de la segunda Nota al embajador de los Estados Unidos en Viena, con lo que la acción colectiva de las potencias se paralizó de manera definitiva. La segunda Nota no será presentada. Es interesante tener en cuenta que el Gobierno británico no comunicó a las otras potencias que desautorizaba la iniciativa de su embajador, con lo que las respuestas negativas de los gobiernos de Alemania, Italia, Francia y Rusia que recibió la iniciativa de Pauncefote tienen que ser entendidas como respuestas a una iniciativa del Gobierno británico.

A partir de este momento ya no quedará ninguna duda sobre el fracaso de la diplomacia española en su esfuerzo para concitar una acción colectiva de las potencias europeas para frenar la intervención de los Estados Unidos en el conflicto cubano.

82 lbidem, pág. 190. 